\title{
Chapter 16 \\ The Unequal Impacts of COVID-19 on Student Learning
}

\author{
João Pedro Azevedo, Marcela Gutierrez, Rafael de Hoyos, \\ and Jaime Saavedra
}

\begin{abstract}
COVID-19 is not only leading to lower student learning levels, but likely resulting in a learning inequality catastrophe. In this chapter, we document the high-levels of learning inequality (within and between countries) that existed before the pandemic and disentangle the different mechanisms through which changes in inequality in learning may happen because of a shock like COVID-19, examining the role of school and family inputs. We show that historically, similar shocks in average learning levels disproportionally affect the most vulnerable students, and that emerging evidence from developed countries, as well as simulations, support the expected significant shifts in the learning distribution. Finally, we present a set of compensatory education policies that countries must urgently implement to reduce the impact of COVID-19 on learning inequality and promote equality of opportunities during and after the pandemic.
\end{abstract}

\footnotetext{
The authors are grateful for the feedback received during the authors' workshop organized in preparation of this book. The findings, interpretations, and conclusions expressed in this paper are entirely those of the authors. They do not necessarily represent the views of the International Bank for Reconstruction and Development/World Bank and its affiliated organizations, or those of the Executive Directors of the World Bank or the governments they represent.
}

J. P. Azevedo · M. Gutierrez $(\varangle) \cdot$ R. de Hoyos · J. Saavedra World Bank, Education Global Practice, 1818 H Street, NW Washington, DC, USA

e-mail: mgutierrezb@worldbankgroup.org

J. P. Azevedo

e-mail: jazevedo@worldbank.org

R. de Hoyos

e-mail: rdehoyos@worldbank.org

J. Saavedra

e-mail: jsaavedra@worldbank.org 


\subsection{Introduction}

The COVID-19 pandemic has generated the worst education crisis of the last century. The health pandemic, its subsequent massive and extended school closures, and the accompanying strain in public and family budgets (that result from one of deepest global economic recessions in history) are unprecedented triple shocks to the human capital of a generation of children. If recovery strategies are not successfully designed and deployed, the intergenerational consequences of this pandemic will be felt for several generations to come.

By early 2021, almost a year after school closures started, World Bank simulations show that learning poverty - the percentage of children who cannot read and understand a simple text by age 10 - could increase from 53 to $63 \%$ in lowand middle-income countries. ${ }^{1}$ It is expected that about 24 million children and youth might not return to school or to a tertiary institution. In addition, there are mental health, nutritional and socialization losses stemming from the lack of interaction among school-aged children and long-term damaging effects over those young children who are still in early childhood.

But the impact of the crisis has been tremendously unequal both between and within countries. First, the timing of the school closures and the priority given to schools reopening at moments when the rates of infection of the pandemic receded, have been vastly different across countries. Second, the capacity of countries to respond with remote education options and its ability to maintain students engaged in the learning process has varied substantially. At the country level, most governments tried to cope with the shock by implementing multimodal remote learning strategies, relying in combinations of internet, TV, radio, and print. But the patterns of take-up of these strategies vary substantially, and its effectiveness remain to a large extend unknown. Poorer countries more frequently relied on radio and TV, while richer countries relied on online education and take-home packages of educational material. Third, household endowments that are important for the learning process and can complement school inputs during school closures are unevenly distributed. Some students have been able to engage with their teachers online, have connectivity, a space to study, books, and supportive parents at home. Others can at most access a few hours a week of radio or TV programming, or nothing at all. All this has generated extremely varied experiences along socioeconomic lines between and within countries.

The potential increase in inequality between countries and within them stemming from COVID-19 might not be surprising if we look at what has happened with inequality in learning in the recent past. Using PISA (Program in International Student Assessments) data, we report that when learning improves, it is usually a tide that raises all boats. However, when learning falls, reductions are not the same across the board but proportionally worse among those at the bottom. In other words, looking

\footnotetext{
1 Azevedo (2020).
} 
at past experience when average learning falls (as will be the case with the COVID19 slide), we can expect that low performing students will suffer disproportionally more.

In this chapter, we document and disentangle the different mechanisms through which changes in inequality in learning may happen because of a shock like COVID19. In doing so, we answer the following questions: (i) what was the status of learning inequality before the pandemic, and how has learning inequality historically behaved in the face of similar shocks?; (ii) What are the causal linkages between COVID19 and student learning outcomes?; (iii) What is the role played by pre-pandemic inequities in determining the impact of COVID-19 on learning inequality?; (iv) How are the remote education strategies implemented by governments around the world mediating the effects of COVID-19 on learning inequality?; and (v) What can governments do to reduce the impact of COVID-19 on learning inequality and promote equality of opportunities during and after the pandemic?

Section 16.2 shows pre-COVID-19 levels of learning inequality both between and within countries and describes how trends in average learning are associated with changes in learning dispersion. Section 16.3 develops a simple conceptual framework to both understand the current levels of learning inequality and how it might change because of the current pandemic. Section 16.4 uses the latest available data from government surveys and high frequency phone surveys to show how the COVID-19 pandemic and the ability of countries and families to mitigate and remediate the expected learning losses are likely to lead to significant shifts in learning inequality. Section 16.5 discusses the types of education policy options that can help mitigate and remediate the expected learning losses prioritizing disadvantaged students. The last section summarizes.

\subsection{A Learning Crisis Characterized by Huge Disparities Between and Within Countries and Classrooms}

Before COVID-19 hit, the world was facing a deep learning crisis with far too many children failing to acquire the basic skills of literacy and numeracy. In fact, 53\% of children aged 10 did not know how to read and understand a simple text-what we refer to as learning poverty. ${ }^{2}$ This high rate of learning poverty reflected the weakness of education systems worldwide; systems that have delivered improvements in schooling but were not adequately organized to equip children with the foundational skill of reading and hence unable to provide them with more complex skills in math, science, and the humanities. Further, this high rate of learning poverty constrains a country's human-capital accumulation, jeopardizing long-term productivity and growth.

The average learning poverty number hides immense variability in learning outcomes both between regions and countries, and within them. For instance, while

\footnotetext{
${ }^{2}$ World Bank (2019), Azevedo et al. (2021b).
} 


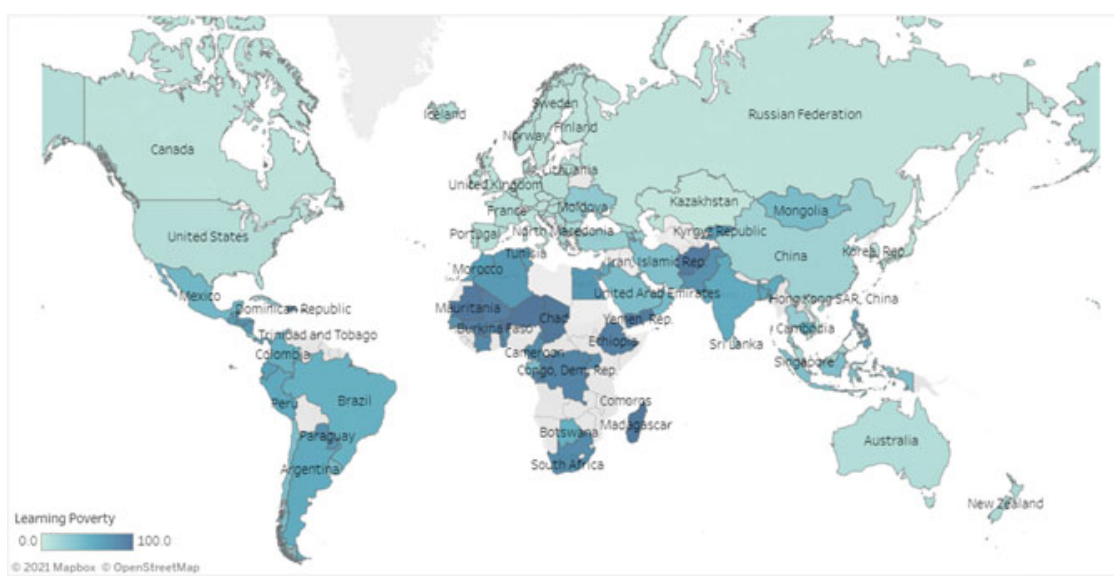

Fig. 16.1 Between country differences in learning poverty. Source EduAnaltyics; Learning Poverty database, The World Bank (October 2019)

learning poverty was $13 \%$ in Europe and Central Asia, it reached almost $80 \%$ of children in Sub-Saharan Africa. Even within Europe and Central Asia-the region with lowest learning poverty rates pre-pandemic - , results varied widely between countries: from $64 \%$ in the Kyrgyz Republic to less than $2 \%$ in the Netherlands (Fig. 16.1). Dramatic variations were also present within countries (Fig. 16.1). In Brazil, a country that had $48 \%$ of children in learning poverty, the within country spatial variation of learning poverty is striking, with rates ranging from the upper 80 s in some North and North-Eastern municipalities, to lower 20s, in municipalities in the state of Ceará, - which is also in the northeast—, or in Sao Paulo (Fig. 16.2). ${ }^{3}$

Children are different; they have different abilities, preferences, speeds of learning, characters. Even in a classroom with little dispersion in socio-economic conditions, there will be a significant heterogeneity in learning achievement. Teachers must deal with this learning heterogeneity, part of which might be explained by differences in socio-economic conditions, or innate ability. This can be illustrated by a series of between- and within-group learning inequality decompositions using data from international learning assessment such as PISA and TIMSS (Trends in International Mathematics and Science Study). Within countries, we observe significant inequalities across the income scale, between urban and rural populations, between girls and boys, and between students in public and private schools. In fact, rurality, gender, income levels, and school characteristics (school fixed effects) accounted for, on average, slightly more than half of the total inequality in learning as measured by

\footnotetext{
${ }^{3}$ The learning poverty number at the municipal level within Brazil is not comparable to the global learning poverty number. The municipal level estimations use the microdata from Prova Brasil 2017, INEP School Census 2017 and IBGE population estimates. The National Minimum Proficiency Level threshold used was 200 points in Portuguese. For more information on the learning results in Ceará see Loureiro and Cruz (2020) and Loureiro et al. (2020).
} 


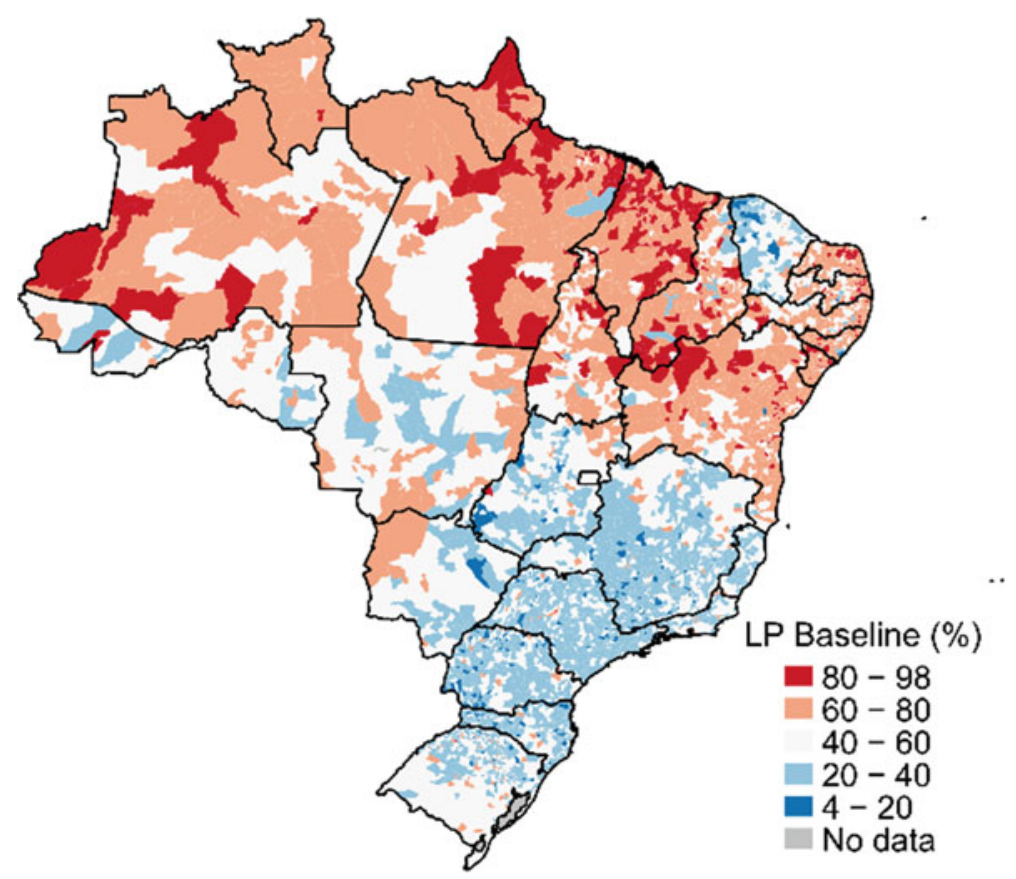

Fig. 16.2 Within country differences in learning poverty. Source Azevedo and Goldemberg (2021). Notes The learning poverty number for Brazil is calculated at the municipal level, using the microdata from Prova Brasil 2017, INEP School Census 2017 and IBGE population estimates. The National Minimum Proficiency Level threshold used was 200 points in Portuguese

standardized tests. ${ }^{4}$ It is important to note the significant heterogeneity of this result across regions and countries. While in East Asia, the Middle East, the Pacific, and Europe and Central Asia, this result varied from 30 to $70 \%$ of the total inequality. In other regions, such as Latin America, such characteristics help explain 50-70\% of total inequality (see Fig. 16.13 for the range of results by regions).

Moreover, student experiences differ significantly within a country, reflecting preexisting inequalities in learning opportunities, which over time reinforce and exacerbate previous disparities. This potential increase in inequality within countries might not be surprising if we look at what has happened in the past when there have been system-wide changes in education performance. Historical data shows that when educational systems improves (i.e., higher share of students above a minimum proficiency level such as the SDG 4.1.1), it is usually a tide that raises all boats (see the green column of Fig. 16.3 which shows that when learning proficiency increased, changes in average scores were responsible for all progress). However, when the share of proficient students falls, reductions are not the same across the board but proportionally worse among those at the bottom of the learning distribution

\footnotetext{
${ }^{4}$ Azevedo and Goldemberg (2020a).
} 
Decomposition of headcount change (\%)
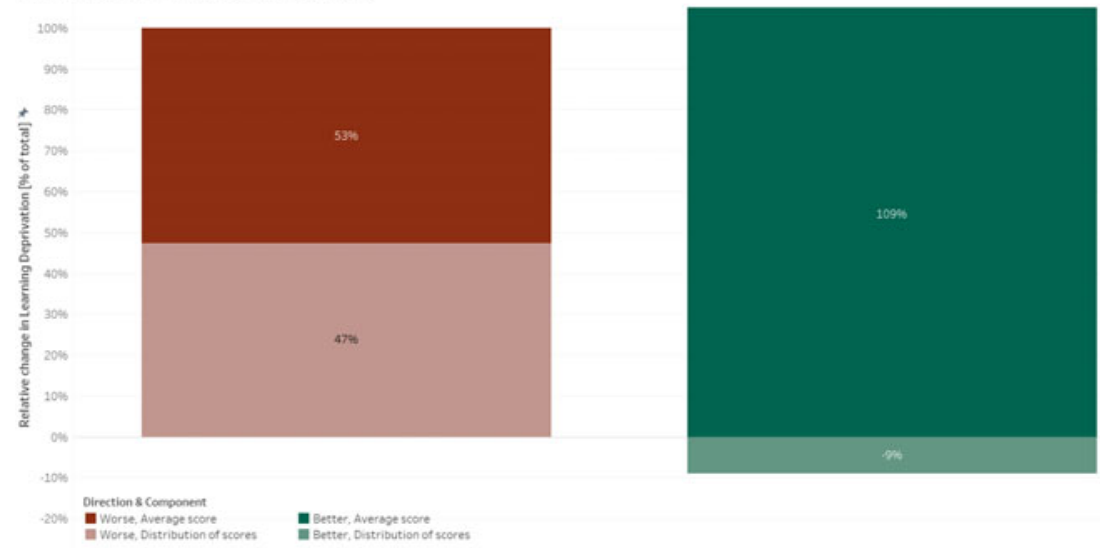

Fig. 16.3 Contributions to changes in the share of learning deprived students of changes in the average score and changes in the distribution of learning. Source Azevedo and Goldemberg (2020a). Note Countries can attain progress in increasing the share of pupils reaching learning proficiency either by improving the outcomes of the average student and/or by focusing in improving the learning of those below the minimum proficiency level. The Figure contains a decomposition of the change in the share of students who score above the Minimum Proficiency level (400 points in the PISA scale) in reading using over 300 observations (each corresponding to a country and pair of years of participation in PISA). See Fig. 16.14 for results per country)

(see the red column of Fig. 16.3 which shows that when proficiency deteriorate, the changes in average scores and inequality each accounted for half of the worsening scores).$^{5}$ In other words, when learning declines, low performing students suffer disproportionally more.

COVID-19 seems to be one large episode in which the share of students above a minimum proficiency level will fall-as some early evidence already shows, as discussed below. Historical data suggests that such past episodes have not been distributionally neutral and have always disproportionally affected more students at the bottom of the learning distribution. Mitigating the impact of COVID-19 on learning disparities will call for the urgent design and implementation of specific compensatory education policies.

\subsection{Why is Learning Unequal and How Might COVID-19 Magnify Such Inequality?}

This section develops a conceptual framework through a simple description of the learning process, which can help explain pre-pandemic levels of learning inequality and how COVID-19 might have magnified them. Most of the discussion in this

\footnotetext{
${ }^{5}$ In the annex we show the country level data behind this calculation.
} 


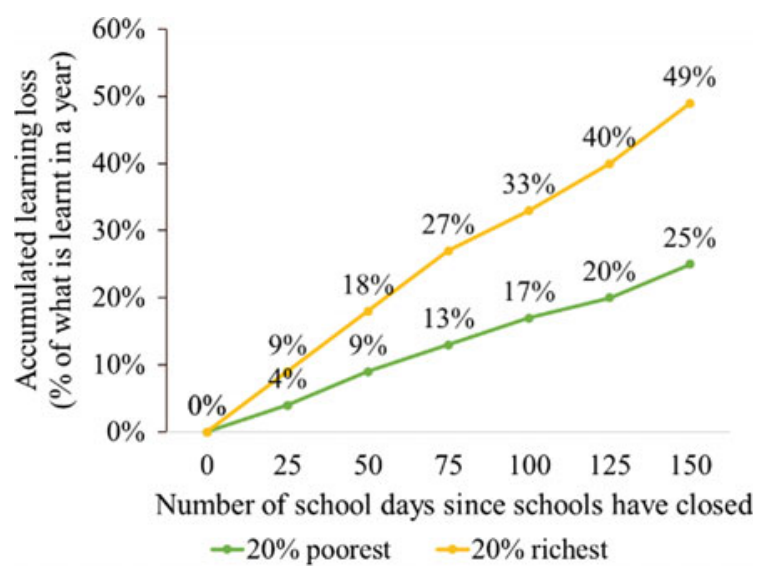

Fig. 16.4 Projected accumulated learning loss for 5th grade students in Colombia- percentage of what is learnt in a year. Source Cerdán-Infantes et al. (2020)

section is based on the well-established relationships between human capital, student learning, and family and school inputs. The framework identifies the potential causal mechanisms explaining the heterogeneous shock of COVID-19 on student learning.

Initial empirical analysis, underpinned by a simple theoretical framework already shows that learning losses could be substantial and unequal, across countries and within countries. For example, country-level estimations in Latin America and the Caribbean, assuming 7-months of school closures, and learning loss mitigation measures with low effectiveness, show that children could lose up to $88 \%$ of what they would have learned in a regular school year, with those in the lowest income quintile losing up to $95 \% .{ }^{6}$ In another study, it is shown that if schools are closed for a whole school year in Chile, students from the lowest income quintile could lose up to $95 \%$ of their yearly learning while those in the highest income could lose up to $64 \% .^{7}$ Simulations in Colombia show that even with partial school reopening, fifth-grade students' learning loss in the bottom quintile could double the top quintile's loss (Fig. 16.4). ${ }^{8}$ Similar estimations hold for Costa Rica, where the poorest students stand to lose close to an additional year of schooling than the richest. ${ }^{9}$ Outside of Latin America, simulations for Indonesia estimate that after four months of school closures, the difference in reading outcomes in PISA between secondary school students in the richest and the poorest quintile will increase from 1.4 years of schooling to 1.6 years of schooling (Fig. 16.5). ${ }^{10}$

Using similar simulations, another World Bank study shows large differences in learning losses across regions. In the scenario of 7 months closures, no remediation

\footnotetext{
${ }^{6}$ World Bank (forthcoming).

${ }^{7}$ Ministerio de Educación de Chile, Centro de Estudios (2020).

${ }^{8}$ Cerdán-Infantes et al. (2020).

${ }^{9}$ Fernández Aráuz (2020).

${ }^{10}$ Yarrow et al. (2020).
} 


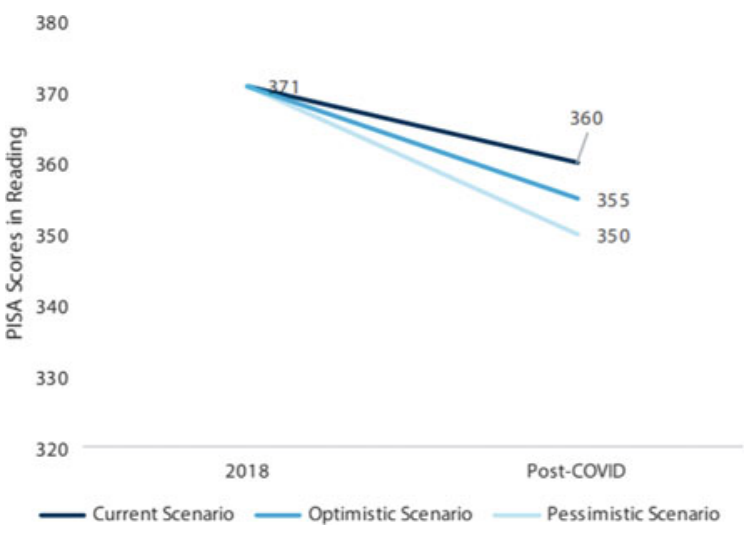

Fig. 16.5 Projected trends in PISA scores in Indonesia under current (4 months), optimistic (6 months) and pessimistic (8 months) scenarios of school closures. Source Yarrow et al. (2020)

and very low mitigation effectiveness in low- and middle-income countries, learning poverty increases by 10 percentage points globally, from 53 to 63\% (Fig. 16.6). SubSaharan Africa and Europe and Central Asia have the smallest absolute increase of learning poverty (5 percentage points), while South Asia has the largest (17 percentage points), followed by Latin America (12 percentage points). Sub-Saharan Africa also has the smallest relative increase ( 5 percentage points), while East Asia and the Pacific and Europe and Central Asia have the largest (more than 30 percentage points), suggesting that children in upper-middle-income and lower-middle-income countries are likely to become the new learning poor.

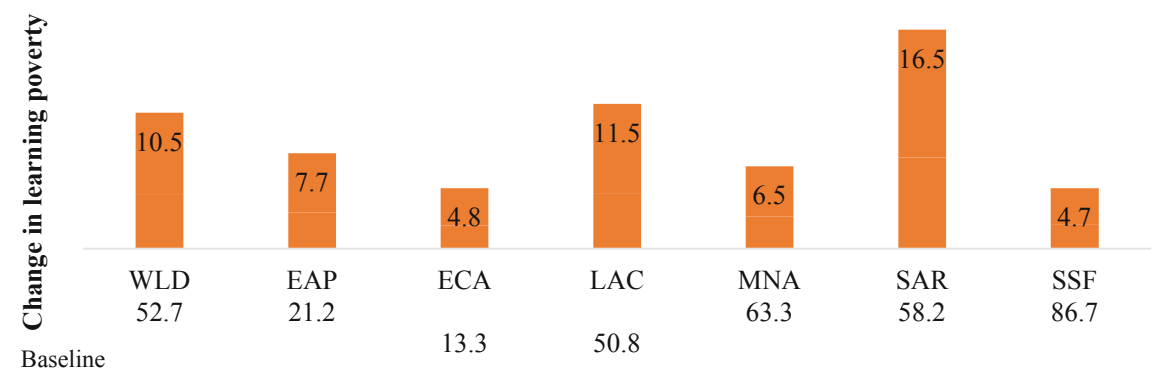

Fig. 16.6 Learning poverty simulation results. Source All underlying numbers can be found in annex Table A.1 in Azevedo (2020) under the pessimistic scenario. Note Simulations for low- and middle-income countries sonly 


\subsubsection{The Technology of Skills Formation ${ }^{11}$}

The stock of human capital or skills, knowledge, and experience of an individual is the outcome of a complex, dynamic, cumulative process involving innate ability and personality traits such as grit and motivation, and parental investment decisions. Schooling is one of the most important parental investment decisions determining student learning $(T)$ and therefore the stock of human capital of individuals. Parents can invest in schooling by paying for the opportunity cost of children not working, investing directly in private schooling, choosing a neighborhood partly based on the quality of public schooling available or making other efforts to enroll their children in a better school. Parental investments also determine the availability of household assets conducive to learning such as learning material, a good learning environment and access to technology. Learning outcomes of student " $i$ " at age " $a$ " are determined by his or her innate and immutable ability $\left(\mu_{i}\right)$, and the flow of past parental investments in the form of family and school inputs, $\boldsymbol{F}_{i}(a)$ and $\boldsymbol{S}_{i}(a)$, respectively ${ }^{12}$ :

$$
T_{i, a}=T_{a}\left(\boldsymbol{F}_{i}(a), \boldsymbol{S}_{i}(a), \mu_{i}\right)
$$

Family and school inputs in Eq. (16.1) have a positive effect on learning outcomes $\left(\partial T_{i} / \partial \boldsymbol{F}_{i}, \partial T_{i} / \partial \boldsymbol{S}_{i}>0\right)$ and $\boldsymbol{F}_{i}(a)$ and $\boldsymbol{S}_{i}(a)$ are complements in the production of learning $\left(\partial^{2} T_{i} / \partial \boldsymbol{F}_{i} \partial \boldsymbol{S}_{i}>0\right)$. These properties of the learning production function have important implications for learning inequality and therefore the distribution of future well-being. Children from better-off parents also enjoy more family inputs at home such as books, technological devices, and most importantly, educated parents creating a positive covariance between family and school inputs. Additionally, rich parents can afford housing in a neighborhood with a high-quality public school or can pay for private schooling with qualified teachers, learning materials, and motivated and committed school directors. The concentration of family and school inputs in better-off households defines the distribution of student learning. Applying $\mathrm{D}\{$.$\} , a$ dispersion or distribution operator, to Eq. (16.1):

$$
D\left\{T_{i}\right\}=T^{\prime}\left(D\left\{\boldsymbol{F}_{i}\right\}, D\left\{\boldsymbol{S}_{i}\right\}, D\left\{\mu_{i}\right\}\right)
$$

The distribution of student learning is defined in terms of the distribution of past flows of family and school inputs, innate abilities, and a covariance between the three terms. Therefore, learning inequality in a point in time, is the outcome of the distribution of past and present family and school inputs, $D\left\{\boldsymbol{F}_{i}\right\}, D\left\{\boldsymbol{S}_{i}\right\}$. Alternatively, if the population of interest is divided into K-mutually exclusive population subgroups, $D\left\{T_{i}\right\}$ can also be expressed in terms of differences in average inputs across the subgroups, $\overline{\boldsymbol{F}}(k), \overline{\boldsymbol{S}}(k), \bar{\mu}(k)$, and the dispersion of inputs within the subgroups,

\footnotetext{
${ }^{11}$ For a formal discussion on skills formation see Cunha and Heckman (2007).

${ }^{12} T_{i, a}$ is determined by $T_{i,(a-1)}$ plus the parental investment at age " $a$ " in the form of family and school inputs, $F_{i}(a)$ and $S_{i}(a)$. Substituting the parental investments in the flow of past student learning outcomes results in Eq. (16.1).
} 
$D\left\{\boldsymbol{F}_{i}(k)\right\}, D\left\{\boldsymbol{S}_{i}(k)\right\}, D\left\{\mu_{i}(k)\right\}$. For instance, inequality in student learning around the world can be expressed in terms of differences in the average level of inputs between countries and how these inputs are distributed within them.

Expression (16.2) is also useful to identify the potential contribution of public policy in shaping learning disparities. In the absence of interventions, the simple human capital accumulation process developed here leads to a society with high learning inequality. More equitable equilibriums require interventions to improve the availability of family inputs among disadvantaged groups via social protection policies or the enactment of education policies to enhance inputs-teachers, management, learning materials-in schools serving disadvantaged students. Cash transfer programs can increase income levels, strengthen nutrition, and even improve parenting through training, all of which can have a positive effect on student learning of vulnerable groups. ${ }^{13}$ Other interventions might improve learning conditions at home by distributing books, computers or other materials to children's households, providing parental training on how to stimulate children and encourage learning at home, and compensate the large inequality in home environments conducive to learning. A more direct and effective way to improving learning outcomes among disadvantaged students is to expand the availability and quality of inputs in schools serving this marginalized groups. Having a physical space dedicated to teaching and learning with an adequate environment and pedagogical materials, and with professionals trained to teach and mentor students, has proven to be a very effective way to improve learning and provide opportunities to poor and disadvantaged students. ${ }^{14}$ In many cases, this equalizing social space disappeared.

\subsubsection{COVID-19, Student Learning and Learning Inequality $^{15}$}

Our simple framework of skills formation helps identify the impact of COVID19 on student learning, which operates through the pandemic's impact on family, school inputs, and government response. All these effects are mediated by the initial distribution of inputs and innate abilities such as perseverance and self-control. In other words, the pandemic can affect the distribution of student learning through three main channels: (1) shifting school inputs, through the choice of the duration and nature of schools closures; (2) the scale and effectiveness of public policies put in place by governments and private providers to mitigate and remediate these schools closures; and (3) the initial family distribution of endowments that can complement

\footnotetext{
13 There is some evidence showing that well-targeted conditional cash transfer programs have positive, though small, effects on student learning.

${ }^{14}$ Banerjee and Duflo (2011).

15 For a rigorous theoretical discussion on the impact of COVID-19 on learning inequality see Agostinelli (2020).
} 
school inputs which will become particularly important as learning moves to the home.

According to the World Bank (2021), the world economy was expected to decrease by $5 \%$ during 2020 - the worse decline since the Great Depression-with many jobs lost, wages cut, and an immediate drop in households' well-being. This macro shock reduced the availability of family inputs, $\boldsymbol{F}_{i}(a)$, which in turn could have reduced students learning outcomes in the short- and long-run. Family inputs are particularly important for the physical and social development of small children going through a critical developmental period. ${ }^{16}$ The average economic shock of the pandemic hides important distributional impacts with households in the lower part of the income distribution bearing a larger share of the burden. ${ }^{17}$ This is partly explained by the unequal possibility across individuals to work from home, which, in turn, is related to differences in occupations and availability of a computer with internet connection at home. Occupations intensive in the use of technology, usually paired with high levels of education, had an easier transition to home-based work. However, less than a third of household heads in developing countries had an occupation that lent itself to be performed through home-based work ${ }^{18}$ and this share is significantly smaller once the availability of internet at home is accounted for. ${ }^{19,20}$

A more evident link between COVID-19 and student learning is through its effects on school inputs, $S_{i}(a)$. Many countries shut down schools to try to reduce the spread of the virus. Education systems had to struggle to use the available resources to continue the learning process, most of them relying on multiple platforms for remote learning, including the use of the internet, mobile phones, T.V., radio, and social media. Given that school inputs were not meant to be used in a context of school closures, lockdowns resulted in a loss of efficiency and productivity, reducing student learning almost immediately. There is plenty of evidence, prior to the COVID-19 pandemic, documenting the negative effects of school closures on student learning. Studies exploiting the "summer meltdown," variations in the number of school days due to teachers' strikes, or extreme climate conditions, show that fewer school days reduce student learning outcomes in core subject areas like math and language. ${ }^{21}$

COVID-19 has also significantly impacted governments' fiscal space, affecting the availability and distribution of funding for the education sector, and the ability of countries to deploy public policies to prevent the worsening of the learning distributions. Before the pandemic, governments were spending vastly different amounts on

\footnotetext{
${ }^{16}$ A recent paper analyzing the effects of the 2005 earthquake in Pakistan, which resulted in schools being closed for several months, shows that children between 0 and 3 years of age at the time of the quake show lower learning outcomes even 4 years after the shock (Andrabi et al., 2021).

${ }^{17}$ Bottan et al. (2020).

18 Dingel and Neiman (2020).

${ }^{19}$ Garrote Sánchez et al. (2020).

${ }^{20}$ Additionally, a significant share of urban households with pre-pandemic incomes under the poverty line derived incomes from activities in the informal sector with little or no scope for working from home (Alfaro et al., 2020).

${ }^{21}$ See Azevedo et al. (2021a) for a discussion on the link between days of schooling and student learning.
} 
education. In low-income countries, the pandemic is expected to reduce education spending in $2021 .{ }^{22}$ Some countries are already cutting their education budgets to make space for the required spending on health and social protection. For example, in Ukraine, the education budget is set for a cut of around $4 \%$ or US\$217 million in 2020 to make more space to deal with COVID-19 related shocks. Reports from Nigeria also suggest that revisions to the federal budget will cut approximately $45 \%$ (US\$130 million) of the budget for the Universal Basic Education Commission. In Kenya, policymakers have identified both development spending on tertiary education and basic education curriculum reform as necessary cuts to support the country's COVID-19 response.

School closures, changes in education budgets and the education policies put in place by governments around the world had a large effect on learning disparities. While there was an overall loss in efficiency of school inputs, less well-off students were in a worse position to weather the storm. Affluent schools were better prepared for remote learning with a more intensive use of technology before the pandemic. With classrooms empty, good teachers and education technology depend on educated parents and availability of inputs (e.g., electricity, connectivity, internet, mobile phone, TV, radio, paper-based-assignments, and books) at home to reach students and produce learning. School closures together with remote learning strategies increased the complementary nature between family and school inputs, making unequal household conditions a more salient determinant of learning inequality.

In developing countries, most students do not have the minimum conditions to learn at home. For instance, in Mexico, an upper middle-income country, only half of the students in basic education-from preschool to 9th grade- had access to a technological device connected to the internet from home, with this share being less than $25 \%$ among students from poor households. Having a device with access to the internet provides students access to online learning and a vast amount of knowledge, but it is not enough to learn. For learning to happen while schools are closed, students, particularly young ones, need an adult (parent or caregiver) with enough time and schooling to teach, guide, and encourage them at home. ${ }^{23}$ Differences in the schooling level and availability of time among parents or caregivers among poor and nonpoor households is one of the most important sources behind the unequal effect of COVID-19 on student learning.

The combination of lack of access to a device with an internet connection, and parents with low education levels and working in the informal sector with little or no time to assist their children in the learning process, makes the impact of school closures highly regressive. The pandemic's regressive effect on family and school inputs combine and reinforce each other to have a significant interruption of the learning trajectories of poor and disadvantaged students. When governments decided to close schools, families changed their behavior to try to cushion the learning disruptions of this decision, but only well-off household had the resources to mitigate the

\footnotetext{
${ }^{22}$ See Al-Samarrai et al. (2020) for a detailed discussion of the expected impacts of the COVID-19 pandemic on education financing.

${ }^{23}$ Banerjee et al. (2007), Bettinger et al. (2020), Escueta et al. (2020).
} 
shock. Highly educated parents in better-off families with secure jobs in the formal sector devoted more time to their children's learning process or invested in private tutoring. Poor households did not have the means to adapt to the new circumstances, absorbing most of the learning shock. While shutting down schools, societies were also shutting down a great social leveler and perhaps one of the few feasible options to escape poverty. ${ }^{24}$

\subsection{What the Data Shows: How Can COVID-19 Impact Learning Inequality?}

This section builds on the conceptual framework introduced in the previous section to provide initial systematic evidence on how the COVID-19 pandemic might impact learning inequality. This section is organized around three main guiding questions, namely: (i) How unequal have COVID-19 school closures been? (ii) How might the current ability of governments to respond to the pandemic affect COVID-19's impact on learning inequality? and (iii) How are pre-crisis inequalities likely to affect the ability of households to ensure learning continuity?

\subsubsection{How Unequal Have the COVID-19 School Closures Been?}

The COVID-19 shock did not affect all countries at the same point of the school year, and offered hugely different conditions for governments to plan, prepare and deploy their mitigation and remediation strategies. In some countries, mostly in the Northern Hemisphere, school closures disrupted the end of a school year; in others, school closures delayed the start of the school year; in still others, school closures coincided with a previously scheduled break. Government's decisions regarding the length of school closures have also varied substantially with some countries closing schools for close to a year now, while some closed them for less than 2 months (Fig. 16.7). Figure 16.7 plots the duration of school closures for a selection of countries chosen to underscore the variety of situations. However, it should be noted that even neighboring countries in the same region experienced vastly different durations and timing of school closure.

\footnotetext{
${ }^{24}$ Glewwe et al. (2017) finds no evidence that schools in Vietnam are more effective for advantaged students. Indeed, the one significant effect is that girls, who some consider disadvantaged, pull ahead of boys between age 5 and 10. In contrast, for two definitions of disadvantage, schools in Peru appear to be more effective for advantaged students. Vietnam's expansion in primary education in the last 2 decades included effective investment in education quality and a focus on equity, emphasizing that all pupils attain "minimum standards." In contrast, Peru's schools suffer from low average quality and high inequality in student learning, with evidence of gaps in access and learning outcomes by, for example, income and ethnicity.
} 


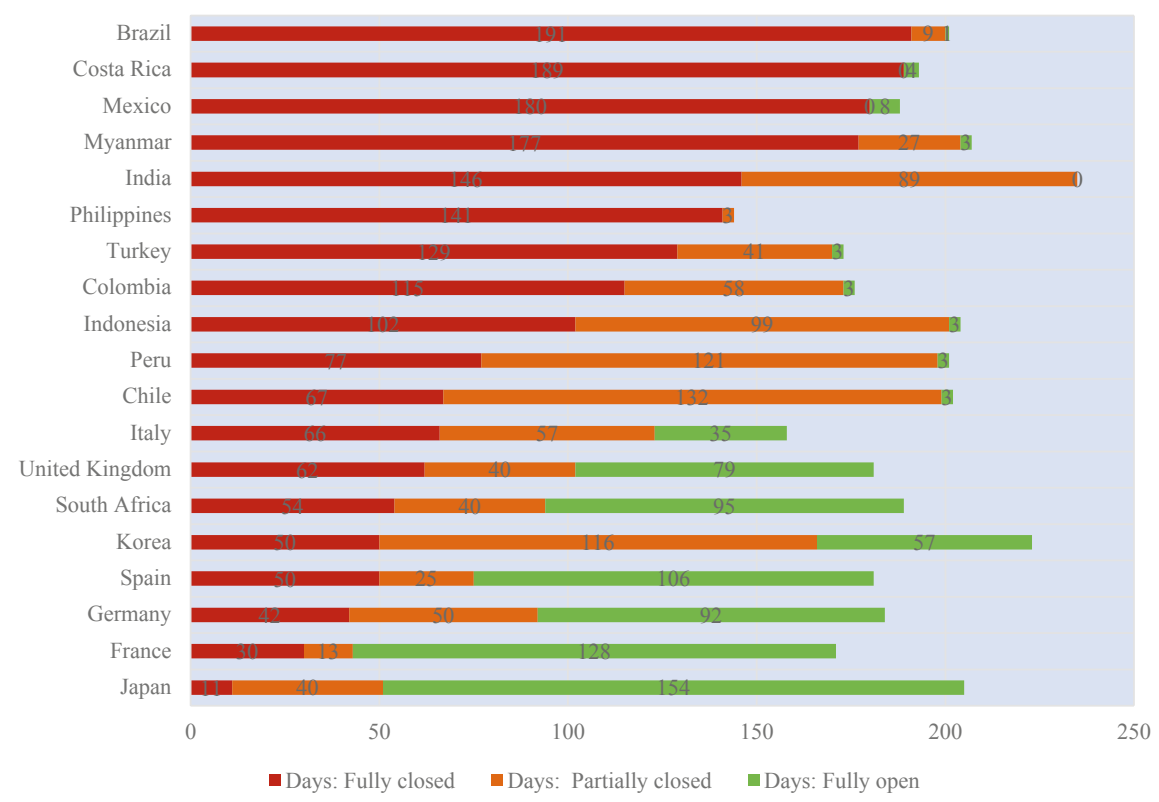

Fig. 16.7 Number of days by school opening status from March 2020 to February 2021, selected countries

In addition, unequal impacts of COVID-19 across gender will also play a significant role in shaping the effect of the pandemic on learning inequality. With schools closed, young girls in low-income settings could spend more time looking after their younger siblings and engaging in other household chores leading to increased disengagement, less learning and eventually higher school dropout. ${ }^{25}$ The rise in anxiety, stress, intra-household violence, and child abuse and neglect, often associated with economic insecurity, will have long-lasting negative impacts on student learning, particularly socio-emotional skills. ${ }^{26}$

There is little evidence regarding the impact of current school closures over learning. However, the mounting evidence-mostly from rich countries-points to relatively low and unequal effectiveness of remote learning. Evidence from a few European countries for which there is learning data post-school closures shows a significant loss of learning, with disadvantaged students suffering the most. In the Netherlands, Belgium, and Switzerland, despite almost universal access to online services, researchers found a decrease in student performance and growing inequality, likely due to children from better-off families receiving more parental support and having better remote learning environments. ${ }^{27}$ In the U.S., regardless of the type of college, enrollment rates for low-income high school students plunged by $29 \%$ in

\footnotetext{
${ }^{25}$ Shores and Steinberg (2020).

${ }^{26}$ Griffith (2020), Bullinger et al. (2020a, b).

${ }^{27}$ Engzell et al. (2020), Bel (2020).
} 
Table 16.1 Impacts of COVID-19 over learning

\begin{tabular}{l|l}
\hline Country & Result \\
\hline Netherlands & $\begin{array}{l}\text { After } 8 \text { weeks of lockdown, students experienced a learning loss of around } \\
\text { 0.08 s.d. (3 pp) which is equivalent to a fifth of a school year (the same } \\
\text { period that schools were closed). Losses were up to 60\% larger among } \\
\text { students from less-educated homes }\end{array}$ \\
\hline United Kingdom & $\begin{array}{l}\text { All groups experienced learning losses: in reading equivalent to } 1.6 \text { to } \\
\text { 2 months, and in math equivalent to over three months. Learning loss is } \\
\text { particularly salient in disadvantaged schools (2.2 months in schools with } \\
\text { high rates of free school meal eligibility vs. 1.5 months in schools with low } \\
\text { rates of free school meal eligibility) }\end{array}$ \\
\hline Belgium & $\begin{array}{l}\text { Significant learning loss with a decrease in math scores of 0.19 s.d. and } \\
\text { Dutch scores of 0.29 s.d. Inequality within schools increased by 17\% and } \\
\text { 20\% for math and for Dutch, respectively. Inequality between schools rose } \\
\text { by 7\% for math and 18\% for Dutch. Learning losses are higher for schools } \\
\text { with more disadvantaged students }\end{array}$ \\
\hline Switzerland & $\begin{array}{l}\text { After } 8 \text { weeks of school closures, primary school students learned more than } \\
\text { twice as fast attending face-to-face learning than with remote learning, and } \\
\text { disparities in learning between students increase substantially. In contrast, } \\
\text { learning for secondary school students was not significantly increased }\end{array}$ \\
\hline
\end{tabular}

Source Engzell et al. (2020), Renaissance Learning, Education Policy Institute (2021), Maldonado and de Witte (2020), Tomasik et al. (2020)

Fall of 2020, a rate that is double that of students from higher-income high schools (Table 16.1). ${ }^{28}$

\subsubsection{How Might the Current Ability of Governments to Respond to the Pandemic Affect Its Impact on Learning Inequality?}

The government responses to these shocks have also been tremendously unequal. First, even if most countries responded to school closures by attempting different mechanisms of remote learning, the access and effectiveness of these efforts has varied widely. Low-income countries relied more frequently on one-way communication strategies, such as radio and TV, while high-income countries are using twoway communication strategies, such as online platforms, leveraged by take-home packages of educational material.

The difference in response, in terms of distance education mechanisms and length of school closures, points to very different experiences between countries, most likely generating a larger divergence in learning inequality between rich and poor countries.

Additionally, within countries, different conditions in school and at home have led to dramatically different experiences for children. Suddenly, and faster than expected,

\footnotetext{
${ }^{28}$ Whitmire (2020).
} 
many teachers were required to become technology experts, digitally connecting with their students, and creating alternative learning routines using digital platforms. If their students had internet access and conditions to work at home, they were able to partially compensate for the lack of in-person classes. Other teachers, whose students only had access to a shared smartphone among different household members, had greater difficulties. These students could follow educational programming on television or radio, but with several siblings in a small house and little room to concentrate, in addition to no space to interact with teachers to ask questions, they had more difficulty learning. And many other students completely disengaged from the educational process. Some students - in countries as diverse as Indonesia, Kenya, and Colombia-were able to easily cope with the changes after schools closed, but not the majority. 2020 marks a different childhood experience that these young people will remember for the rest of their lives, one that will impact their skills and economic prospects for the rest of their lives.

A UNESCO-UNICEF-World Bank Joint survey of school closures applied in late 2020 asked Ministries of Education what policies were being put in place to prevent the exclusion of learners without access to remote learning. As mentioned above, most countries implemented multiplatform strategies, with very different patterns across countries. The differences between countries are striking. One third of lowincome countries (33) have declared that they have not taken any measures to reduce the risk of students 'exclusion from remote learning, a result that is six times higher compared to high-income countries (Fig. 16.8). High and middle-income countries were significantly more likely to roll out measures that would entail flexible and self-paced platforms. These platforms ranged from asynchronous learning platforms (which allow each learner greater flexibility and the freedom to advance at his or

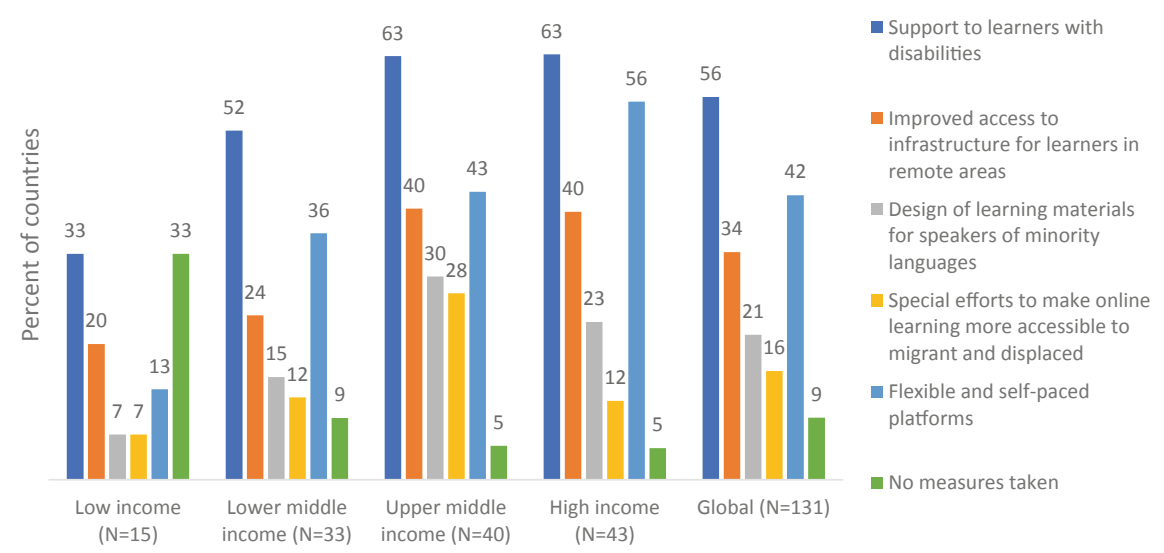

Fig. 16.8 Measures for students at risk of exclusion from remote learning, by country income group. Source Authors' calculations using UNICEF/UNESCO/World Bank joint survey 


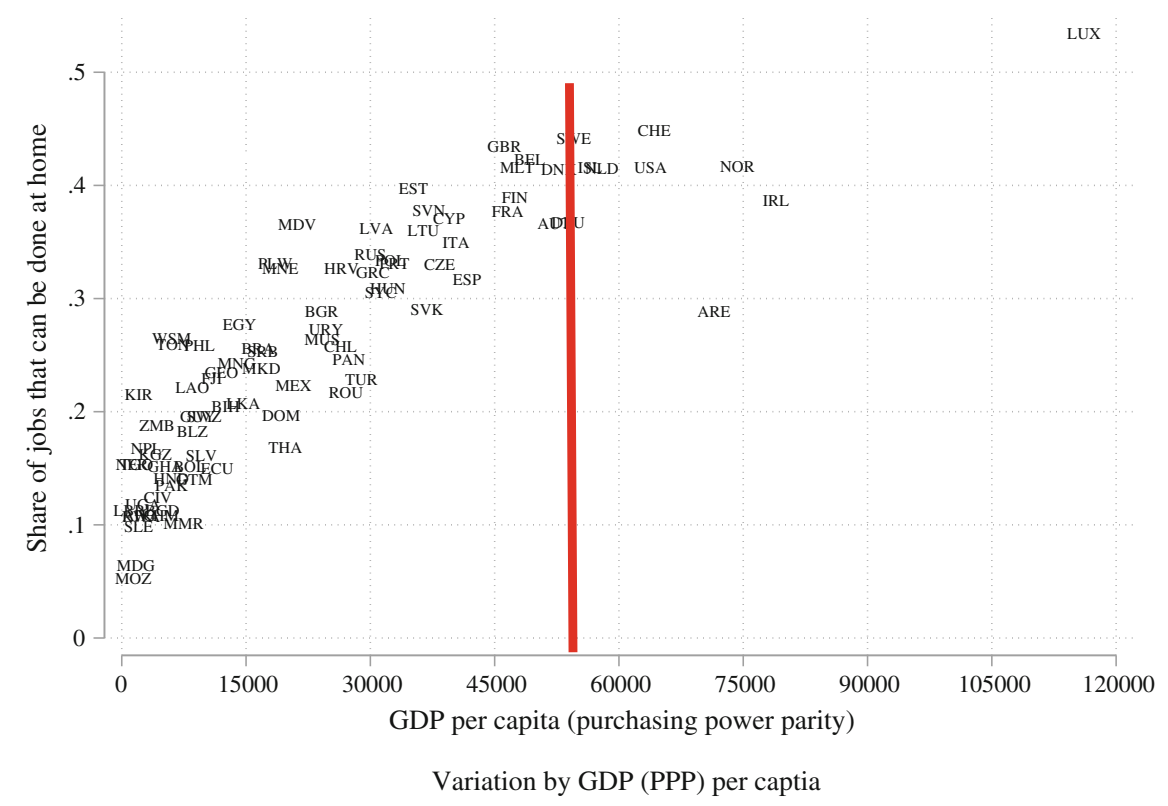

Fig. 16.9 Working from home and per capita GDP. Source Dingel and Neiman (2020)

her own speed, thus integrating various learning habits), to using school facilities to support learners in need and those at risk of dropout and disengagement. ${ }^{29}$

\subsubsection{How Are Families' and Household's Pre-COVID Inequalities and Post-COVID Behavior Likely to Magnify the Learning Crisis?}

As described above, the economic shock that resulted from COVID-19 has been highly unequally distributed between and within countries, with households in the lower part of the income distribution bearing a larger share of the burden. The unequal distribution of the economic shock is partly explained by pre-pandemic differences in labor market conditions, with formal, high-skilled, occupations lending themselves to be performed at home and more precarious ones more exposed to lockdowns. As shown in Fig. 16.9, less than a third of households in developing countries - to the left of the vertical line in Fig. 16.9 - had an occupation that lends itself to be performed through home-based work. ${ }^{30}$ Additionally, a significant share of urban households

${ }^{29}$ UNESCO, UNICEF, The World Bank (2020b).

${ }^{30}$ Dingel and Neiman (2020). 


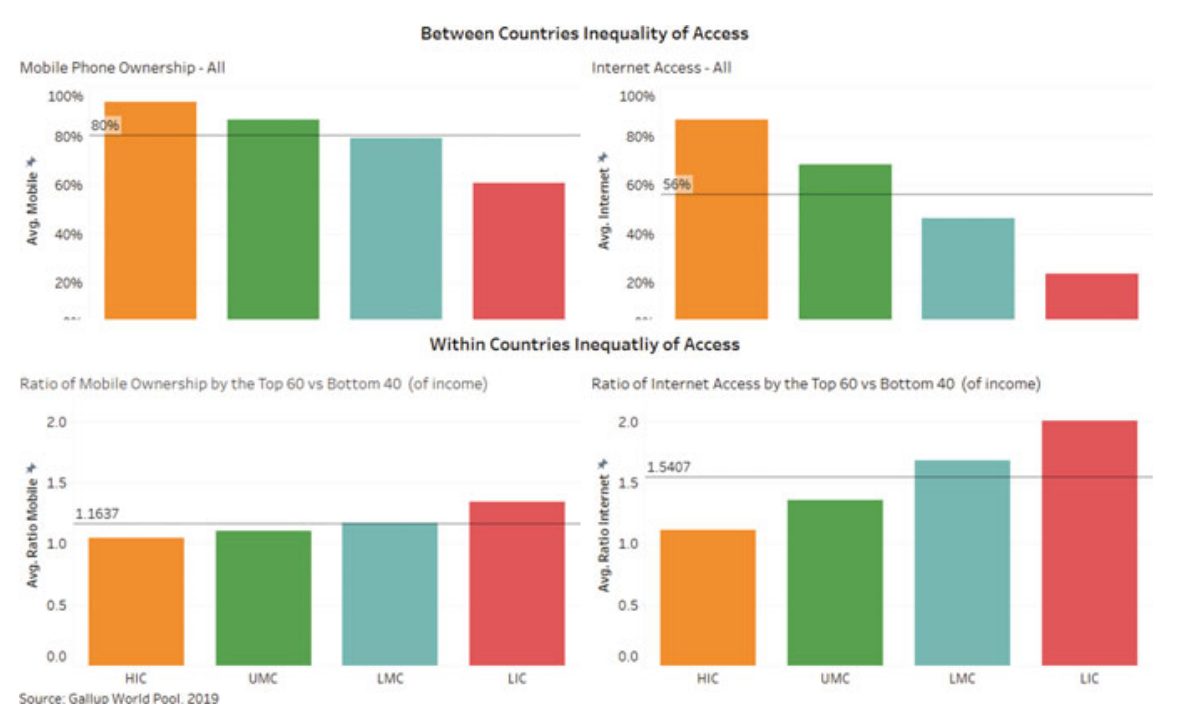

Fig. 16.10 Between and within country variation on ownership and access to mobile phones, by country income groups. Source Authors' calculations using Gallup World Poll (2019)

with pre-pandemic incomes under the poverty line derived incomes from informal sector activities with little or no scope for working from home. ${ }^{31}$

The occupational characteristics of individuals in poor households made them less adept to lockdowns, bearing a disproportional shock from the pandemic. Evidence from previous economic crises shows that student learning suffers from negative income shocks. ${ }^{32}$ Parents have less time and resources to make sure that there are minimum household conditions for learning; in low-income settings, nutritional inputs can be compromised, or children might be encouraged to enter the labor market, all of which reduces student learning.

A second pre-pandemic inequality shaping the learning incidence of COVID-19 is the availability of devices with access to the internet. Figure 16.10 shows the highly unequal distribution of access to a mobile phone or internet between and within countries. Mobile ownership reaches $94 \%$ in high income countries, and only $61 \%$ in low-income countries. Internet access reaches $87 \%$ in rich countries but only $24 \%$ in poorer ones. Moreover, within countries inequality in access varies dramatically. In rich countries for example, access to internet does not differ much between the bottom $60 \%$ and the top $40 \%$ in the income scale. In low-income countries, access rates double among the top $40 \%$.

Perhaps the most important element shaping the unequal learning impacts of the pandemic is the pre-existing differences in parental schooling. More educated parents were not only more adept to changes in labor market conditions, but they

\footnotetext{
${ }^{31}$ Alfaro et al. (2020).

32 Shafiq (2010); Shores and Steinberg (2017).
} 


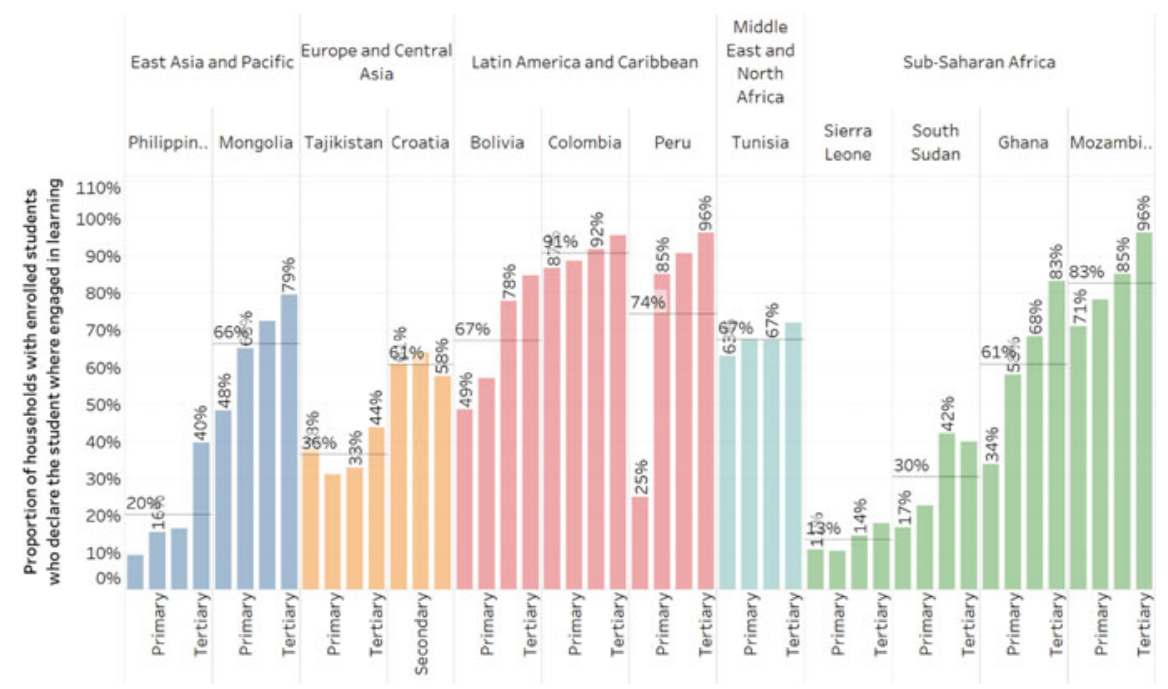

Fig. 16.11 Household learning engagement in the last 7 days, in selected countries by household's highest level of adult education. Source Authors' calculations using World Bank High-Frequency Phone Survey (2020). Note Survey responded at the household level. Responses reference 7 days. Latin American responses from Wave 1 were removed to avoid a different reference window

were also more likely to have the content knowledge to help their children during home schooling. Parents or caregivers with more education are also more aware of the importance that learning outcomes play in shaping their children's future labor market opportunities which encouraged them to actively participate in home schooling activities. Figure 16.11 shows the learning engagement level of students for countries in different regions by the highest level of education of adults in the household. Once again, both between- and within-group learning inequalities are likely to increase, as the level of learning engagement during the pandemic is drastically higher for children of highly educated parents. While more than $80 \%$ of students from households with a highly educated adult (tertiary education) have remained engaged in learning during the period of school closures, engagement is much lower in households with adults with lower education levels. In several countries, students from households where adults had no education were 3 to 4 times less likely to be engaged in a learning activity during the same period. 


\subsection{Education Policies to Mitigate and Remediate Learning Losses}

As we saw in the previous sections, COVID-19 not only led to decreased learning but likely resulted in a learning inequality catastrophe. Countries urgently need to implement compensatory measures to avoid turning the temporary shock into a permanent one. Some of these measures can be implemented once schools re-open, while others need to be implemented as soon as possible, complementing remote learning interventions. Certainly, all the compensatory policies need a careful design, training for those responsible for implementing them on the ground, a rollout strategy, and above all, the necessary financial resources and political leadership.

In the short-term, a critical task of education systems is to avoid that the potential impacts of COVID-19 described above transform into student disengagement and an eventual school dropout. Therefore, compensatory education policies should identify and reach out to students suffering the most and keep them engaged to ensure that they return to school once re-open. As shown in Fig. 16.12, strategies to encourage reenrollment include information and communication campaigns, financial and nonfinancial incentives, early warning systems with targeted support interventions, and special education programs for pregnant girls when banned from school.

Once schools re-open, at least in a hybrid way, the focus should be on compensating learning losses and providing more support for those students that suffered the most from the pandemic. To help those with the biggest learning gaps catch-up, countries can measure the extent and the incidence of the learning loss and implement compensatory education policies including additional teaching time, specific pedagogies targeted at those furthest behinds (such as teaching to the right level methodologies), tutoring or accelerated learning programs (see Fig. 16.12). ${ }^{33}$

Given fiscal and operational limitations, it is important to ensure that resources are allocated efficiently. One option is for Ministries of Education to implement a combination of system-wide responses to address the generalized learning loss at a national level (such as streamlining the curriculum) ${ }^{34}$ and more targeted strategies (such as tutoring and teaching to the right level) to tackle the inequality of the learning loss. For the targeted strategies, Ministries could consider allocating resources and technical assistance to schools based on their share of disadvantaged students. In low-capacity contexts, it might be necessary to provide direct support to schools to implement the compensatory measures, with the support of NGOs (non-governmental organizations) or volunteers. In contexts where the school and regional levels have the necessary capacity, Ministries could consider creating a menu of compensatory options and transferring funds to schools or districts to select the compensatory measures that might work best for their student population. The selection of context-adequate compensatory options could be done with the technical guidance of central-level

\footnotetext{
${ }^{33}$ Mundy and Hares (2020).

${ }^{34}$ For instance, France will provide teachers with guides explaining the prioritized objectives for the grade once schools open in the fall.
} 

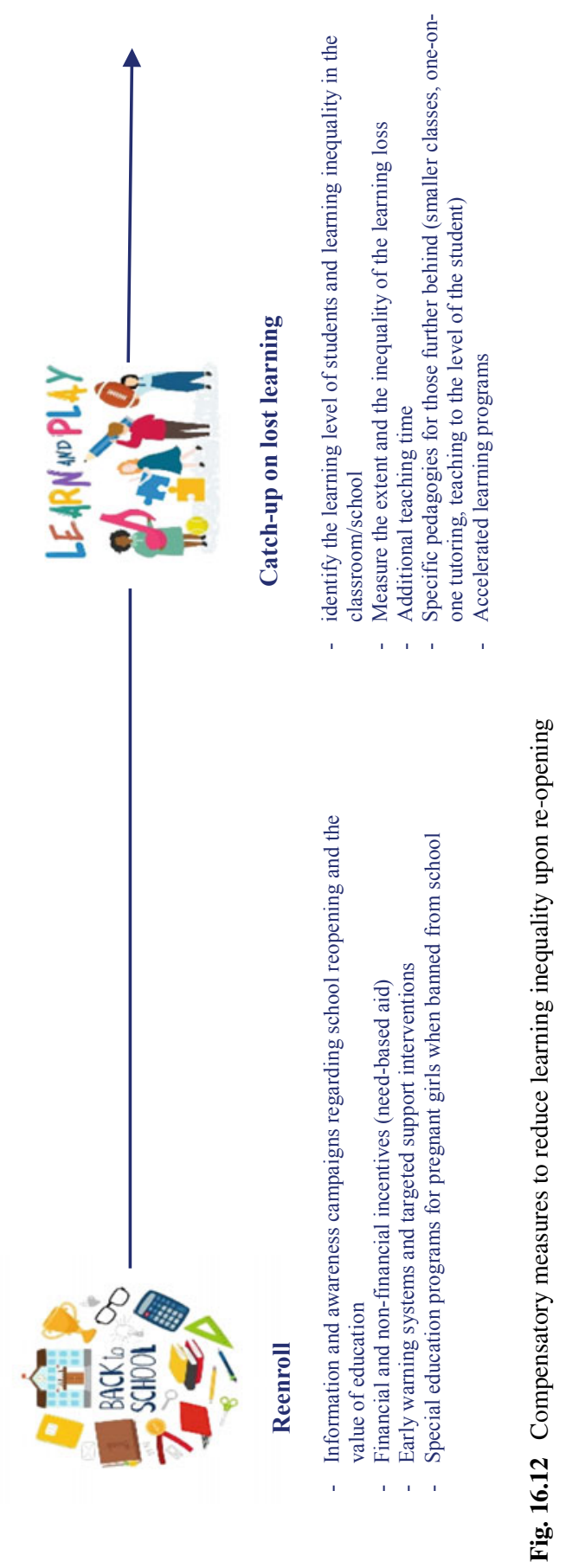
education authorities. The remaining elements of this section describe some education interventions for which there is some evidence showing that they effectively increase student reenrollment and, once in school, improve learning.

\subsubsection{Compensatory Measures to Increase Reenrollment}

To avoid disengagement with the learning process and increase reenrollment, policymakers can consider providing information to students and parents on the availability of distance education programs, school re-opening plans, school safety protocols, and income-earning benefits of education. In their most basic form, information and awareness campaigns can inform parents of the available distance or hybrid education programs, school re-opening plans (e.g., dates, location), and the process to get children back to school. ${ }^{35}$ To tackle the fear of contagion while in schools, campaigns can also involve messaging regarding school safety protocols and on showing the evidence of low transmission of COVID-19 for the youngest. Importantly, including specific and context-relevant information on the returns to education might be useful in increasing enrollment (and attainment) in contexts where that information shifts the beliefs of youth and parents (for instance, where youth have limited exposure to highly educated individuals in their communities that are successful in the labor market). ${ }^{36}$ The latter has been tested positively in small-scale interventions in Madagascar, Peru, and the Dominican Republic. ${ }^{37}$

The provision of information cannot wait for schools to re-open; communications must be continuous so that the linkage between the student and the school stays active and disengagement is averted. For instance, an RCT (randomized clinical trial) in Pakistan is evaluating the effect of an intervention that includes lesson plans, SMS (Short Messaging Services), and phone messages to encourage take-up of distance education; as well as SMS with information on school re-opening plans, school scholarships, the returns of learning, and other social returns to encourage reenrollment. ${ }^{38}$ Re-enrollment campaigns are also being implemented in Madagascar, Ethiopia, Pakistan, and Sierra Leone, focusing on students most at risk of dropping out (girls and students from marginalized communities). The Philippines is implementing a multi-pronged strategy to bring children back to school, which involves more flexible enrollment procedures, teachers tracking each student's enrollment, and a strong media campaign (involving Facebook, Twitter, local T.V., and radio). ${ }^{39}$

\footnotetext{
${ }^{35}$ Ludvigsson (2020), Munro and Faust (2020), Dattner et al. (2020), Rajmil (2020), Heavey et al. (2020), Isaacs et al. (2020).

${ }^{36}$ Global Education Advisory Panel (2020), Adelman and Székely (2017).

${ }^{37}$ Nguyen (2008), Neilson et al. (2016), Jensen (2010).

${ }^{38}$ SIEF (2020).

${ }^{39}$ The flexible procedures include accepting enrollments after the start of the school year, extending deadlines for documentation to enroll, and creating new spaces for enrollment to take place. UNESCO (2020a).
} 
Early-warning systems (EWS) could be used to identify children and youth at risk of disengaging with learning and not returning to school and providing them targeted support. EWS uses data on risk factors that contribute to dropout (e.g., attendance, academic achievement) to identify students at risk and provide them with interventions to help them stay in school. These interventions can include SMS/calls to encourage children to participate in distance learning, provide them with distance learning materials, and notify parents when children do not engage or do not reenroll; virtual (online, phone, SMS) one-on-one support from teachers or volunteers; extracurricular activities; mentoring schemes; remediation classes; psychosocial support; counseling; or even monetary and non-monetary incentives. EWS is most effective in countries where there is sufficient student data, where dropout is not widespread, and where schools can support students that are identified as at risk. ${ }^{40}$ In fact, while they have reduced absenteeism in the USA (United States of America), in the Netherlands, in Cambodia, and in Serbia (albeit in a small-scale pilot), they have not been impactful in Tajikistan, India, and Timor-Leste. ${ }^{41}$ To respond to COVID-19, Salvador (Brazil) is combining accelerated learning recovery programs with the system-wide expansion of an EWS where Agentes da Educação monitor school attendance and visit families of at-risk youth to prevent dropout. ${ }^{42}$

Although the impact has not yet been widely measured, multiple countries are using technology-enabled support to complement distance education delivery for the most vulnerable during COVID-19. In Italy, the provision of 3.6 weekly hours of free individual online tutoring by volunteer university students significantly impacted students' academic performance, socio-emotional skills, and psychological wellbeing. Importantly, the effects were greater for those of lower socio-economic backgrounds and immigrants. ${ }^{43}$ In Botswana, weekly SMS with math problems and 1520-min phone calls to walk through the problems significantly increased student learning during school closures. ${ }^{44}$ Similar interventions are being tested in other countries. In Bangladesh, researchers are evaluating the effect of SMS messages, teacher outreach, and a reduction of internet cost over student engagement with the governments' distance learning platform, student learning, and socio-emotional wellbeing. In Ecuador, researchers evaluate the effect of sending SMS reminders to encourage students to complete their online training along with incentives (a weekly lottery ticket for a prize upon completing learning modules) and benchmarking for underperforming students. In Ghana, an RCT is testing the impact of sending SMS messages that suggest activities to promote socio-emotional development at home and encourage remote learning. In Guatemala, the impact of radio skits with early childhood stimulation messages and voice messages to encourage uptake is also being evaluated. Finally, the impact of SMS reminders to listen to the radio distance

\footnotetext{
${ }^{40}$ UNICEF (2018).

41 Faria et al. (2018), De Witte and Cabus (2010), Mathematica (2015), Jovanović et al. (2017), Early (2015), Mathematica (2015).

42 World Bank (forthcoming).

43 Carlana and La Ferrara (2021).

44 Angrist et al. (2020).
} 
program and a complimentary phone tutorial by teachers is being evaluated in Sierra Leone. $^{45}$

When the reasons for not returning to schools are financial, it might be useful to offer incentives that offset the financial opportunity costs of returning and increase the immediate benefits of getting back to school. These incentives can be financial (such as awarding scholarships, fee waivers, or conditional cash transfers) or non-financial (such as free school meals or materials-e.g., books, uniforms, meals, transport, radios, tablets). ${ }^{46}$ Properly targeted cash transfers have consistently shown positive effects on enrollment and dropout rates in contexts where school participation is low. ${ }^{47}$ For them to be impactful, it is crucial to target children that might not continue schooling otherwise because of financial pressures or high opportunity costs outside school. Scholarships can be ineffective when not well-targeted or when the real constraint driving dropouts is academic rather financial. ${ }^{48}$

After the Ebola crisis, Sierra Leone drove re-enrollment rates to $95 \%$ by ensuring minimum safety protocols (soap, veronica buckets), using massive awareness campaigns (radio jingles, back-to-school committees with parents), training on the provision of psychosocial support, and waiving school fees including children's' books. In response to COVID-19, multiple countries are providing similar incentives. For instance, UNICEF is working with Airtel Africa in 13 sub-Saharan African countries to provide mobile cash transfers to families of 133 million school-aged children encouraging reenrollment and online learning. ${ }^{49}$

Offering pregnant girls special education programs can also be critical to increase engagement with schooling and re-enrollment, especially in countries with a ban on pregnant girls attending school. During the Ebola crisis of 2014, Sierra Leonean schools were closed for eight months. Upon re-opening, girls ages 12-17 were 16 percentage points less likely to be in school. Child labor by girls increased by 19 percentage points. ${ }^{50}$ In some communities, teenage pregnancy increased by up to $65 \%$ due to the socio-economic conditions imposed by the outbreak. ${ }^{51}$ During that time, the country had banned visibly pregnant girls from returning to schools or sitting for examinations. This led to a generation of young mothers that saw their future truncated. Thankfully, in March 2020, the government reversed this ban and implemented the Zero Schoolgirl Pregnancy Campaign that involves strong messaging to Chiefs, religious leaders, the police, nurses, parents, teachers, and girls themselves around the importance of protecting and investing in girls, enhancing sexual reproductive health education; reducing maternal teenage death to zero; enhancing school completion and transition, and supporting the health of girls. ${ }^{52}$

\footnotetext{
${ }^{45}$ SIEF (2020).

46 Adelman and Székely (2017).

${ }^{47}$ Global Education Advisory Panel (2020).

48 de Hoyos et al. (2019).

${ }^{49}$ UNESCO (2020a).

${ }^{50}$ Bandiera et al. (2018).

${ }^{51}$ Onyango et al. (2019).

${ }^{52}$ Calimoutou (2020), Sierra Network (2020).
} 


\subsubsection{Compensatory Measures to Catch up Lost Learning}

Countries must start by assessing student learning to understand how to best align their practices and teaching material to the students' needs. In countries where a sufficiently recent learning assessment is available, it should be possible to design a temporary comparable instrument and use it to measure the extent of the learning losses. ${ }^{53}$ Countries need to understand both the extent of the learning loss and whether all students in each classroom/school/district/or country were impacted similarly. Countries do not have to wait until school re-opening to measure the current level of learning their students, and potentially their learning loss. For instance, the Ministry of Education and Technical Education of Egypt adapted their examinations so that students in grades 3-9 are evaluated through open-book multidisciplinary research projects done from home, and students in grades 10-11 rely on computer-based tests from home. ${ }^{54}$ Ghana and Rwanda will also test remote formative assessments using basic mobile phone technologies to support learning outside of physical classrooms. France plans to follow a more traditional route by conducting early year assessments for grades 1, 6 and 12, and providing sample tests for teachers to assess student learning at a classroom level. ${ }^{55}$

Increasing the instructional time might be a way to catch up on lost learning during closures. This could entail having a greater number of hours each school day (through longer school days or shorter recess time), extending the school week (through weekend school), offering summer school, or having an early school start or late school end. The school day's expansion has shown consistently positive impacts on learning in the United States, Ethiopia, Peru, Chile, Colombia, Uruguay, and Argentina. ${ }^{56}$ Rigorous global evidence suggests that summer or after school programs can lead to important learning gains for the most disadvantaged. ${ }^{57}$ According to the UNESCO, UNICEF, World Bank Survey of National Education Response to COVID19 School closures, almost a quarter of educational systems plan to increase class time in the second half of the year. ${ }^{58}$ For example, France allocated $€ 200$ million to provide "learning vacations," which will be fully-funded for children of modest backgrounds. Through this program, one million children can go to their regular schools, a summer camp in the countryside or coastal areas, learning summer camps, or learning leisure centers to catch up on learning and play. ${ }^{59}$

${ }^{53}$ UIS and ACER have recently designed a strategy for Monitoring the Impacts on Learning Outcomes (MILO), using recently implemented Regional Learning Assessment, such as PASEC (2019) or National Learning Assessments as baselines, and designing temporally comparable instruments.

54 OECD, World Bank, Global Education Innovation Initative, hundrED (2020).

55 UNESCO (2020b).

${ }^{56}$ Patall et al. (2010), Murnane and Ganimian (2014), Orkin (2013), Agüero (2016), Bellei (2009), Pires and Urzua (2014), Hincapié (2016), Cerdán-Infantes and Vermeersch (2007).

${ }^{57}$ McLaughlin and Pitcock (2009), Allensworth and Schwartz (2020), Snipes et al. (2016).

${ }^{58}$ UNESCO, UNICEF, World Bank (2020a, b, c).

${ }^{59}$ Ouest-France (2020). 
Individual students that are particularly behind their peers might require dedicated attention, such as one-to-one or small group tutoring, once schools re-open. ${ }^{60}$ Existing evidence shows that high-dosage tutoring (at least 4 times per week) with a small group of students (less than 6 children) substantially impacts learning, especially if conducted during school hours. ${ }^{61}$ For instance, having recent college graduates provide one-to-one tutoring to high school students in Boston for four days per week led to learning gains equivalent to one or two additional years of math in a single school year, above and beyond what students typically learn. In Niger and Nigeria, a $6 \mathrm{~h}$ per week tutoring program targeting displaced and refugee children also had significant impacts on student's reading and math, especially when accompanied with socio-emotional learning activities (mindfulness and Brain games). ${ }^{62}$ Programs that combine cognitive-behavioral therapy with academic tutoring have also shown substantial effects on students' dropout rates in at-risk communities in the United States and Canada. ${ }^{63}$ However, a math tutoring intervention and a cognitive-behavioral therapy-based program in Mexico, which had limited take-up, found mixed effects on socio-emotional skills and no effect on math scores. ${ }^{64}$ When designing tutoring programs, incentives must be carefully designed. As documented by several scholars, private tutoring can cause negative distortions on the education system when teachers offer for-profit tutoring to their same students. This gives them a pervasive incentive to teach less during their regular classes to generate demand for tutoring. ${ }^{65}$

To respond to COVID-19, $62 \%$ of countries plan to introduce a dedicated remedial program. For instance, England set up a $£ 1$ billion fund with two branches: $£ 350$ million will be directed to ensure the most disadvantaged pupils can access tutors over the year, and $£ 650$ million will be directed to primary and secondary schools who will have the choice to provide additional 1-on-1 or group tutoring for any pupils that they identify need it. ${ }^{66}$ France will fund 1.5 million additional teaching hours so that all students have the option of taking at least $3 \mathrm{~h}$ of homework support per week under the Devoirs faits program (which offers voluntary homework support). ${ }^{67}$ The Philippines also issued a plan where students who earn less than a $75 \%$ grade receive remedial classes for six weeks. As an alternative, schools have the option to organize make-up classes for the upcoming year. ${ }^{68}$

\footnotetext{
${ }^{60}$ Evidence for Learning; Elbaum et al. (2000).

${ }^{61}$ Education Endowment Foundation; Nickow et al. (2020), Allensworth and Schwartz (2020), Robinson et al. (2021).

62 3EA (2017).

63 Adelman and Székely (2017).

${ }^{64}$ Avitabile et al. (2019).

65 Bray and Lykins (2012), Dang (2007), Jayachandran (2014), Azam (2016), Bray et al. (2014), Bray (2003), Ille (2015).

${ }^{66}$ Richardson (2020).

${ }^{67}$ UNESCO (2020b).

${ }^{68}$ Ibid.
} 
Initiatives to target instruction by learning level, instead of grade or age, are worth considering as an alternative to catch-up on learning. These programs involve grouping students by their level of knowledge with instruction designed to continuously assess their progress and scaffold knowledge to advance to the next level. Different modalities involve grouping students for all or part of the school day; grouping them during school, in after-school classes, or during summer-camps; relying on government teachers, volunteers, or teaching assistants. These programs have been implemented successfully in several settings, including Kenya, Ghana, Zambia, India, and Brazil. ${ }^{69}$ Under the Acelera Brasil program, students were divided into separate classes according to their needs. Those that were lagging the most received supplementary classes that allowed them to catch up. Within five years, $52 \%$ of participating students in the State of Paraíba passed more than one grade and rejoined their appropriate age group. In the State of Pernambuco, the dropout rate was significantly lower than the average after the program was implemented $(3.2 \%$ vs. $14.8 \%$ ). In the State of Tocantins, $99 \%$ of the program graduates were promoted to the next level. ${ }^{70}$ In India's Balsakhi Program, a tutor from the local community worked with a group of 15-20 children who were falling behind their peers for two hours each day (out of the 4 total school hours). In this time, the tutor focused on improving core competencies having substantial positive impacts on learning. ${ }^{71}$

Computer-assisted software can aid in tailoring instruction to the students' needs and can be used while schools are closed and relying on online platforms to deliver distance learning. For instance, in an intervention in Vadodara (India), which had statistically significant improvements in learning outcomes, grade four students accessed two hours of shared computer time per week to play math games that responded to their ability. ${ }^{72}$ Another rigorously studied intervention with very positive impacts provided after school instruction 6 days per week, with 45 min of individual self-driven learning using the Mindspark app, followed by $45 \mathrm{~min}$ of guided group learning (using a teaching assistant and $12-15$ students). ${ }^{73}$ Similar interventions in advanced countries (and in Uruguay at a national level) have also found positive results, particularly for the most vulnerable. ${ }^{74}$ Post COVID-19, the Government of Ecuador plans to improve students' academic readiness with important curricular knowledge gaps by providing Adaptive Computer Assisted Remediation Programs for 12 months to 16,000 first-year students in 90 technical institutes nationwide. ${ }^{75}$

Finally, accelerated learning programs can reduce learning inequality. These programs aim to complete the education outcomes in a shorter period and normally provide an alternative route to return to learning for those behind their age-peers after dropping out of education. Such programs have been implemented in Afghanistan,

\footnotetext{
${ }^{69}$ Duflo et al. (2011), Banerjee et al. (2017).

${ }^{70}$ UNESCO (2020b).

${ }^{71}$ Banerjee et al. (2007).

72 Muralidharan et al.(2019).

${ }^{73}$ Banerjee et al. (2007).

${ }^{74}$ Escueta et al. (2017), Perera and Aboal (2017).

${ }^{75}$ Angel-Urdinola (2020).
} 
Bangladesh, Brazil, Burundi, Cambodia, Ghana, Honduras, Liberia, Malawi, Sierra Leone, Tanzania, Mali, Burkina Faso, Niger, and Ethiopia, among others.

Most of these interventions have focused on primary, small multi-age, and multigrade classes. In several cases, community-based volunteers have been used as facilitators, who were supported with detailed lesson plans and a streamlined curriculum focusing on foundational and relevant learning. Often, these programs have started with mother-tongue instruction, for at least 3-4 h per day, and were introduced as a time-bound response to a crisis (e.g., conflict). Some of them have been successful in terms of access, completion, retention, and learning. ${ }^{76}$

Although interventions were exposed separately, governments will likely need to design a package of multiple interventions to keep students engaged, get them to reenroll and support them in staying and succeeding at school. These interventions might complement each other, as seen in a multifaceted program in India which involved door-to-door campaigns to enroll girls who had either dropped out or had never enrolled in school, activity-based and playful teaching to students grouped by ability, stronger school management communities, and work with the community to promote girls' education. This intervention was successful in increasing enrollment ( $8 \%$ in the first year and $12 \%$ in the second), reducing gender gaps in school retention, increasing learning $(0.3$ s.d. in the first year and 0.16 in the second year) and improving school management. ${ }^{77}$

\subsection{Concluding Remarks}

Learning depends on a set of school and family inputs, and innate ability and motivation. Variances in the availability of those inputs will generate different learning outcomes. The availability of both family and school inputs differ by income and socioeconomic status and the effects of these two inputs is compounded by the complementarity between them. On one hand, more equitable equilibriums require interventions to improve the availability of family inputs among disadvantaged groups via social protection policies or direct assistance to improve learning conditions at home (connectivity, devices, learning materials). On the other hand, governments need to enact education policies to enhance inputs (teachers, management, learning materials) in schools serving disadvantaged students.

When governments decided to close schools, the highly unequal distribution of family inputs both between and within countries, such as access to a mobile phone or internet and parental levels of education, took on greater importance. Differences in school inputs were already generating inequality of opportunities before the pandemic. But now, differences in conditions at home started being more relevant in defining variation in education opportunities. As shown here, there are large differences in the availability in critical inputs across countries and within them. For

\footnotetext{
${ }^{76}$ Longden (2013).

${ }^{77}$ Delavallade et al. (2019).
} 
example, internet access reaches $87 \%$ in rich countries but only $24 \%$ in poorer ones. Moreover, inequality in access varies dramatically within countries. In rich countries for example, access to internet does not differ much between the bottom $60 \%$ and the top $40 \%$ in the income scale. In low-income countries access rates are double for the top $40 \%$.

But the difference in these inputs interacts with the differences in parental education. We find that engagement level of students varies markedly according to the level of education of adults in the household. Learning inequalities are likely to increase, as the level of learning engagement during the pandemic is drastically higher for children of highly educated parents. While more than $80 \%$ of students from households with a highly educated adult (tertiary education) have remained engaged in learning during the period of school closures, engagement is much lower in households with adults with lower education levels; in several of the countries, students from a less well-off background (adults with no education) were 3-4 times less likely to be engaged in a learning activity during the same period.

Learning data post-pandemic is not available yet, except for a few European countries which report learning losses equivalent to the extent of the school closures and highly unequal, despite smaller differences in family and school inputs, along the income scale. Using data for some middle-income countries, we complement this analysis with simulations of learning losses by quintile of income. If schools are closed for a whole school year in Chile, students from the lowest income quintile could lose up to $95 \%$ of their yearly learning while those in the highest quintile could lose up to $64 \%$. Simulations for Colombia show that even with partial school reopening, fifth-grade students' learning loss in the bottom quintile could double the top quintile's loss. In Indonesia it is estimated that after only four months of school closures, the difference in reading outcomes in PISA between secondary school students in the richest and the poorest quintile will increase from 1.4 years of schooling to 1.6 years of schooling.

COVID-19 is not only leading to potentially lower learning but likely resulting in a learning inequality catastrophe. Hence, countries urgently need to implement compensatory measures to avoid turning the temporary increases in inequality into permanent ones. Some of these measures can be implemented once schools re-open, while others need to be implemented as soon as possible, complementing remote learning interventions.

In the short-term, a critical task of education systems is to avoid that the potential impacts of COVID-19 described above transform from student disengagement and an eventual school dropout. Therefore, compensatory education policies should identify and reach out to students suffering the most and keep them engaged to ensure that they return to school once they re-open. Strategies to encourage reenrollment include information and communication campaigns, financial and non-financial incentives, early warning systems with targeted support interventions, and special education programs for pregnant girls when banned from school.

Once schools re-open, at least in a hybrid way, the focus should be on compensating learning losses. To help those with the biggest learning gaps catch-up, countries 
need to urgently measure the extent and the incidence of the learning loss and implement compensatory education policies, including additional teaching time, specific pedagogies targeted at those furthest behind (such as teaching to the right level methodologies), and tutoring or accelerated learning programs.

\section{Annex I-Complementary Figures}

See Figs. 16.13, 16.14, 16.15, 16.16 and 16.17.

\section{Annex II-Description of Data Sources}

- Microdata from international learning assessments: PISA and TIMMS

- World Bank High-Frequency Phone Survey (2020)

- UNESCO-UNICEF-World Bank Joint Survey of Government Responses

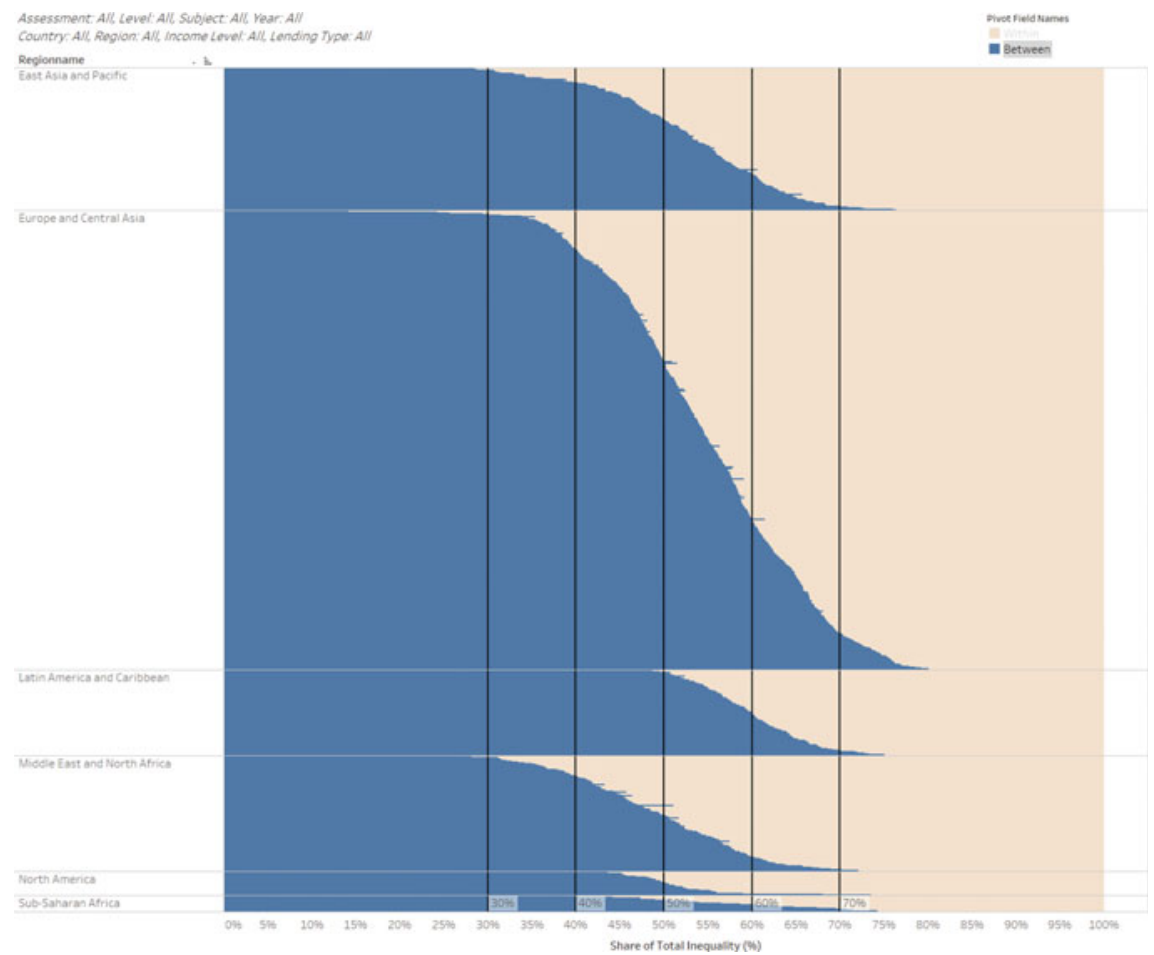

Fig. 16.13 Distribution of, between, and within country learning inequality by region, accounting for rurality, gender, income levels, and school characteristics 


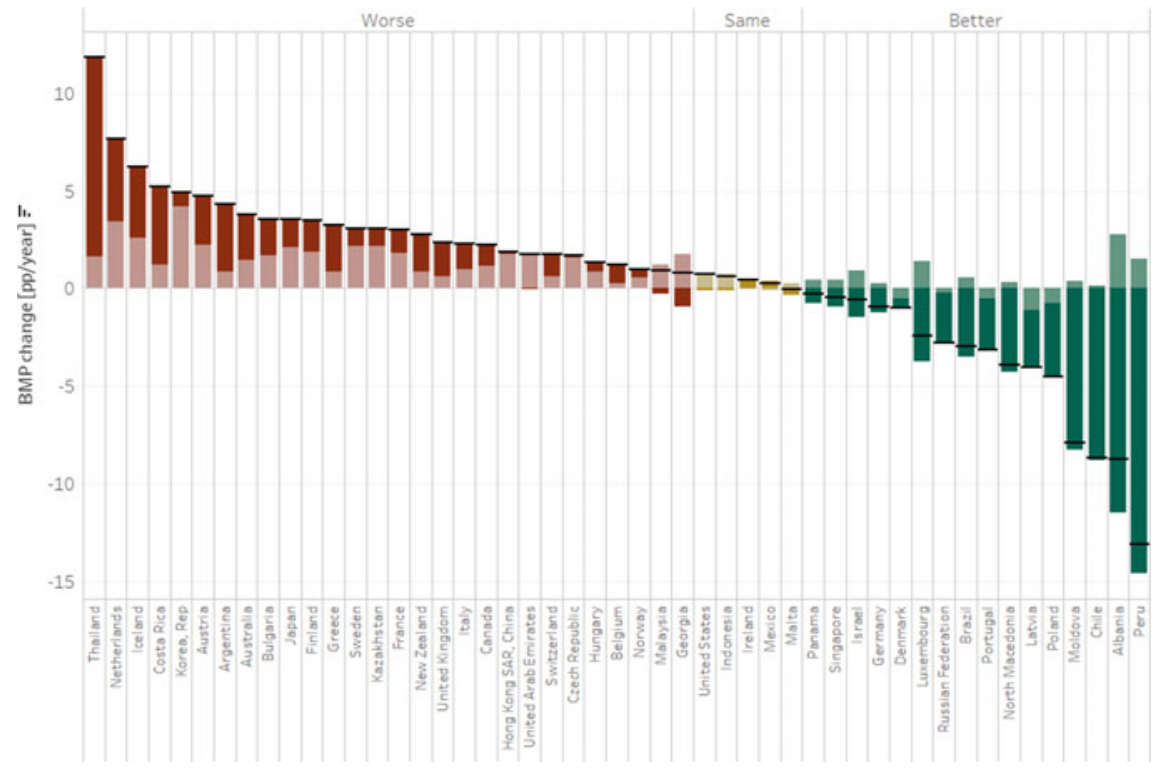

Fig. 16.14 Changes in Below Minimum Proficiency, decomposing by changes in average proficiency and changes in distribution. (Datt-Ravallion Decomposition). Source Azevedo and Goldemberg (2020b)

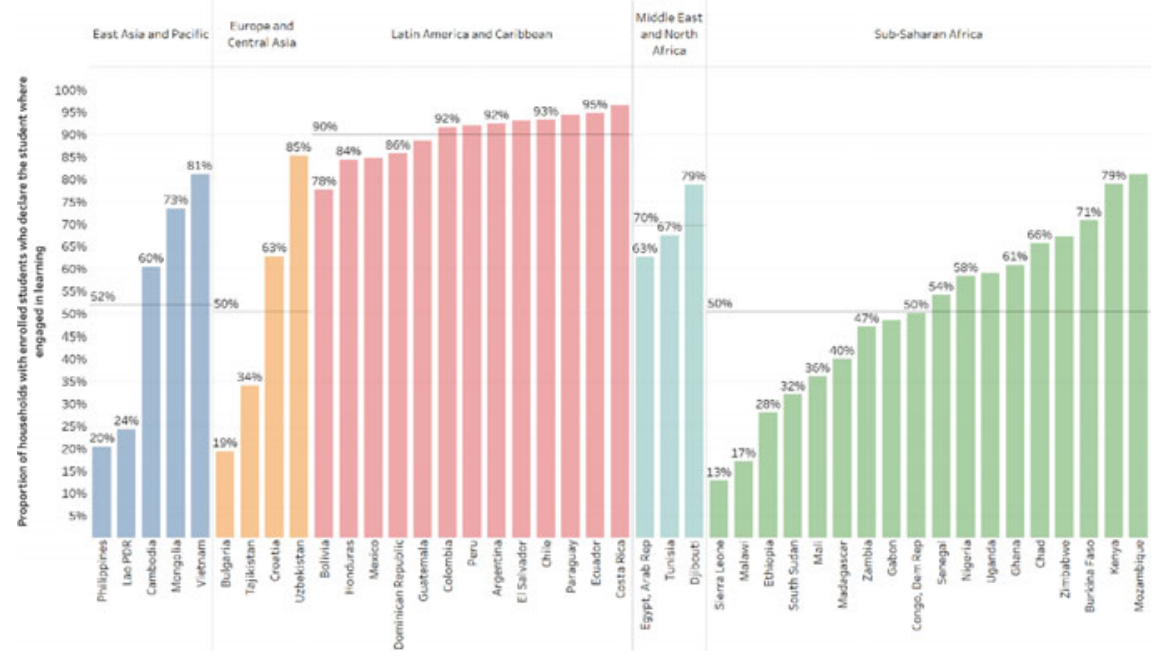

Fig. 16.15 Share of household learning engagement in the past 7 days, by Country. Source Author's calculation using the World Bank High-Frequency Phone Survey (2020). Note Survey responded at the household level. Responses reference 7 days. Latin American responses from Wave 1 were removed to avoid a different reference window 


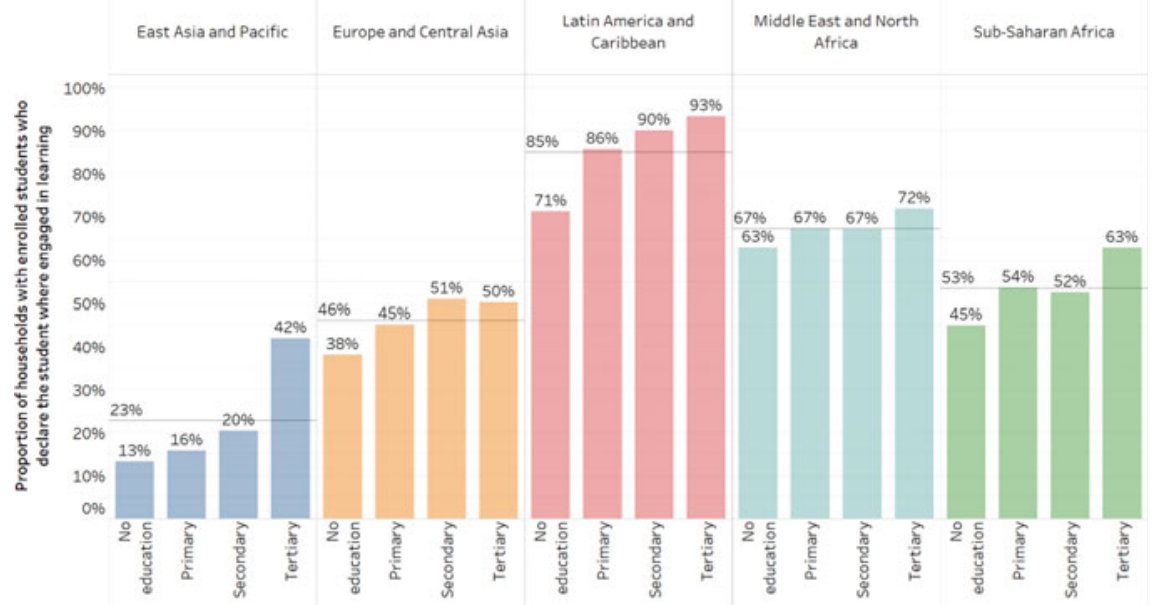

Fig. 16.16 Share of household learning engagement in the past 7 days, by Region and Highest Adult Educational Level. Source Author's calculation using the World Bank High-Frequency Phone Survey (2020). Note Survey responded at the household level. Responses reference 7 days. Latin American responses from Wave 1 were removed to avoid a different reference window

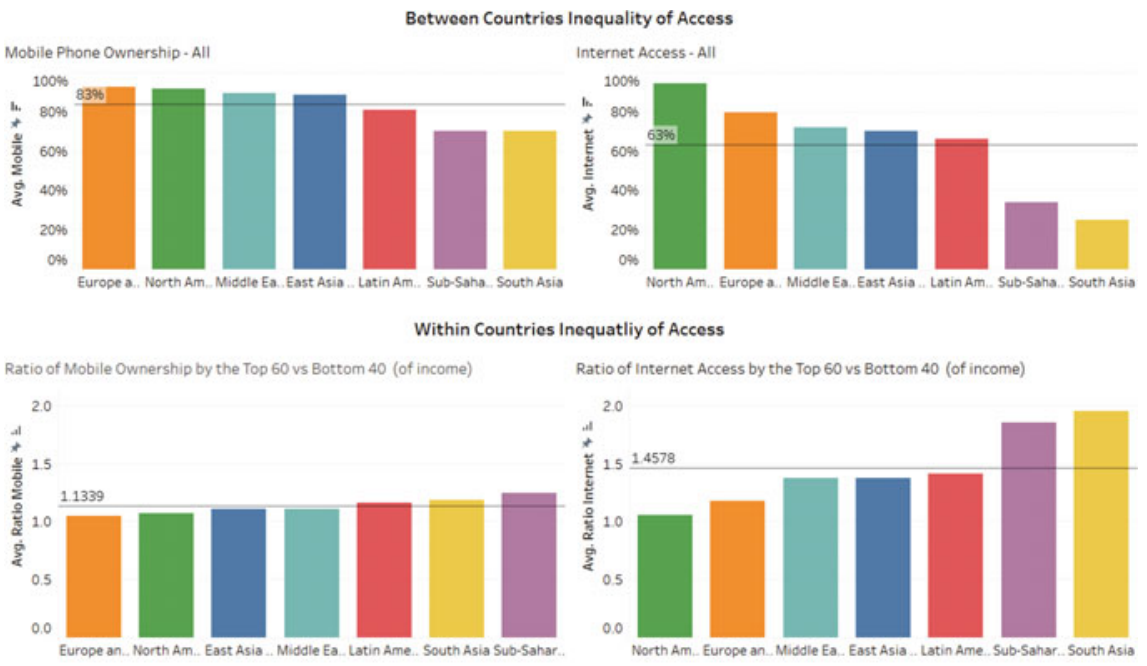

Source: Galluo World Pool. 2019

Fig. 16.17 Between and within country variation on ownership and access to mobile phones by region 
- Gallup World Pool, 2019

- World Bank Learning Poverty Database

- SAEB and Brazilian School Census.

\section{References}

3EA, Education in Emergencies Evidence for Action. (2017). IRC healing classrooms remedial tutoring programming improves Nigerien and Nigerian children's learning. Retrieved February 26, 2021, from https://research.steinhardt.nyu.edu/scmsAdmin/media/users/mhm327/ 3EA-Niger_Impact_Brief_2.1.pdf.

2020 «Vacances apprenantes»: Jean-Michel Blanquer, le ministre de l'Éducation dévoile le mode d'emploi. Viewed 10 January, 2020, https://www.ouest-france.fr/education/vacances-scolaires/ vacances-apprenantes-mode-d-emploi-1-etat-finance-1-ete-d-un-million-d-enfants-6860038.

Adelman, M. A., \& Székely, M. (2017). An overview of school dropout in Central America: Unresolved issues and new challenges for education progress. European Journal of Educational Research, 6(3), 235-259.

Agostinelli, F., Doepke, M., Sorrenti, G., \& Zilibotti, F. (2020). When the great equalizer shuts down: Schools, peers, and parents in pandemic times (No. w28264). National Bureau of Economic Research.

Agüero, J. (2016). Evaluación de impacto de la Jornada Escolar Completa. Repositorio institucional - GRADE. Retrieved November 22, 2019, from http://repositorio.grade.org.pe/handle/ GRADE/378.

Alfaro, L., Becerra, O., \& Eslava, M. (2020). EMEs and COVID-19: shutting down in a world of informal and tiny firms (No. w27360). National Bureau of Economic Research.

Al-Samarrai, S., Gangwar, M., \& Gala, P. (2020). The impact of the COVID-19 pandemic on education financing. Economic Impact of COVID-19. World Bank, Washington, DC. https://ope nknowledge.worldbank.org/handle/10986/33739.

Allensworth, E., \& Schwartz, N. (2020). School practices to address student learning loss. EdResearch for Recovery. https://annenberg.brown.edu/sites/default/files/EdResearch_for_Rec overy_Brief_1.pdf.

Andrabi, T., Daniels, B., \& Das, J. (2021). Human capital accumulation and disasters: Evidence from the Pakistan earthquake of 2005. Journal of Human Resources, 0520-10887R1.

Angel-Urdinola, D. (2020). Use of adaptive computer assisted remediation programs to prevent student dropout in the context of COVID-19. Education for Global Development. https://blogs.worldbank.org/education/use-adaptive-computer-assisted-remediation-pro grams-prevent-student-dropout-context-covid.

Angrist, N., Bergman, P., Brewster, C., \& Matsheng, M. (2020). Stemming learning loss during the pandemic: A rapid randomized trial of a low-tech intervention in Botswana. Available at SSRN 3663098.

Avitabile, C., Cuevas, J., de Hoyos, R., \& Jamison, J. C. (2019). Addressing high school dropouts with a scalable intervention: The case of PODER. The World Bank.

Azam, M. (2016). Private tutoring: Evidence from India. Review of Development Economics, 20(4), 739-761.

Azevedo, J. P., \& Goldember, D. (2020a). Learning for all: Beyond an average score. Published at Education for Global Development series of the Wold Bank Blogs. Retrieved October 22, 2020, from https://blogs.worldbank.org/education/learning-all-beyond-average-score.

Azevedo, J. P., \& Goldember, D. (2020b). Learning for all: Within-country learning inequality. Published at Education for Global Development series of the World Bank Blogs. November 12th, 2020. https://blogs.worldbank.org/education/learning-all-within-country-learning-inequality. 
Azevedo, J. P. (2020). Learning poverty: Measures and simulations (Policy Research Working Paper No. 9446). World Bank, Washington, DC. http://hdl.handle.net/10986/34654.

Azevedo, J. P., \& Goldemberg, D. (2021). Estimating the potential COVID-19 impacts on learning poverty in Brazil-An update. World Bank.

Azevedo, J. P., Hasan, A., Goldemberg, D., Geven, K., Iqbal, S. A. (2021a). Simulating the potential impacts of COVID-19 school closures on schooling and learning outcomes: A set of global estimates. The World Bank Research Observer, 36(1), 1-40. https://doi.org/10.1093/wbro/lka b003.

Azevedo, J. P., Goldemberg, D., Montoya, S., Nayar, R., Rogers, H., Saavedra, J., \& Stacy, B. W. (2021b). Will every child be able to read by 2030? Defining learning poverty and mapping the dimensions of the challenge (Policy Research Working Paper; No. 9588). World Bank, Washington, DC. https://openknowledge.worldbank.org/handle/10986/35300.

Bandiera, O., Buehren, N., Goldstein, M., Rasul, I., \& Smurra, A. (2018). The economic lives of young women in the time of Ebola.

Banerjee, A. V., \& Duflo, E. (2011). Why aren't children learning?" Dev Outreach (April), (13), 36-44. https://doi.org/10.1596/1020-797X_13_1_36.

Banerjee, A., Banerji, R., Berry, J., Duflo, E., Kannan, H., Mukerji, S., Shotland, M., \& Walton, M. (2017). From proof of concept to scalable policies: Challenges and solutions, with an application. Journal of Economic Perspectives, 31(4), 73-102.

Banerjee, A. V., Cole, S., Duflo, E., \& Linden, L. (2007). Remedying education: Evidence from two randomized experiments in India. The Quarterly Journal of Economics, 122(3), 1235-1264.

Bel, T. (2020). Inequality in homeschooling during the Corona crisis in the Netherlands. First results from the LISS Panel. SocArXiv, 30 April 2020. Web. https://osf.io/preprints/socarxiv/hf32q/.

Bellei, C. (2009). Does lengthening the school day increase students' academic achievement? Results from a natural experiment in Chile. Economics of Education Review, 28(5), 629-640. Pires and Urzua (2014).

Bettinger, E., Fairlie, R. W., Kapuza, A., Kardanova, E., Loyalka, P. K., \& Zakharov, A. (2020). Does EdTech substitute for traditional learning? Experimental estimates of the educational production function. NBER Working Paper (w26967).

Bottan, N., Hoffmann, B., \& Vera-Cossio, D. (2020). The unequal impact of the coronavirus pandemic: Evidence from seventeen developing countries. PloS One, 15(10), e0239797.

Bray, M., \& Lykins, C. (2012). Shadow education: Private supplementary tutoring and its implications for policy makers in Asia (No. 9). Asian Development Bank.

Bray, M. (2003). Adverse effects of private supplementary tutoring: Dimensions, implications, and government responses. UNESCO.

Bray, M., Zhan, S., Lykins, C., Wang, D., \& Kwo, O. (2014). Differentiated demand for private supplementary tutoring: Patterns and implications in Hong Kong secondary education. Economics of Education Review, 38, 24-37.

Bullinger, L., Carr, J. B., \& Packham, A. (2020a). COVID-19 and crime: Effects of stay-at-home orders on domestic violence (NBER Working Paper No. 27667).

Bullinger, L., Raissian, K., Feely, M., \& Schneider, W. (2020b). The neglected ones: Time at home during COVID-19 and child maltreatment (August 1, 2020). Social Science Research Network.

Calimoutou. (2020). Sierra Leone took a major first step towards keeping girls in school and inclusive education. World Bank Blogs. https://blogs.worldbank.org/nasikiliza/sierra-leone-tookmajor-first-step-towards-keeping-girls-school-and-inclusive-education.

Carlana, M., \& La Ferrara, E. (2021). Apart but connected: Online tutoring and student outcomes during the COVID-19 pandemic.

Cerdán-Infantes, P., \& Vermeersch, C. (2007). More time is better: An evaluation of the full-time school program in Uruguay. World Bank Policy Research Working Paper (4167).

Cerdán-Infantes, P., Zavala Garcia, F., Suarez Gomez, J. C., Guallar, S., Márquez de Arboleda, A., De La Cadena Becerra, S., \& Vergara Rojas, S. (2020). The education impact of the COVID-19 crisis and political response in Colombia (Impactos de la Crisis del Covid-19 en la Educacion y Respuestas de Politica en Colombia.). World Bank. Retrieved November 22, 2020, from 
Dang, H. A. (2007). The determinants and impact of private tutoring classes in Vietnam. Economics of Education Review, 26(6), 683-698.

Dattner, I., Goldberg, Y., Katriel, G., Yaari, R., Gal, N., Miron, Y., Ziv, A., Hamo, Y., \& Huppert, A. (2020). The role of children in the spread of COVID-19: Using household data from Bnei Brak, Israel, to estimate the relative susceptibility and infectivity of children. MedRxiv.

de Hoyos, R., Attanasio, O., \& Meghir, C. (2019). Targeting high school scholarships to the poor: The impact of a program in Mexico (No. w26023). National Bureau of Economic Research.

De Witte, K., \& Cabus, S. J. (2010). Dropout prevention measures in the Netherlands, an evaluation. Belgium.

Delavallade, C., Griffith, A., \& Thornton, R. L. (2019). Effects of a multi-faceted education program on enrollment, equity, learning, and school management: Evidence from India. World Bank Policy Research Working Paper (9081).

Dingel, J. I., \& Neiman, B. (2020). How many jobs can be done at home? Journal of Public Economics, 189, 104235.

Duflo, E., Dupas, P., \& Kremer, M. (2011). Peer effects, teacher incentives, and the impact of tracking: Evidence from a randomized evaluation in Kenya. American Economic Review, 101(5), $1739-1774$.

Early, D. (2015). Do early warning systems and student engagement activities reduce dropout? USAID.

Education Endowment Foundation. Small group tuition. Consulted in: https://educationendowment foundation.org.uk/evidence-summaries/teaching-learning-toolkit/small-group-tuition/.

Elbaum, B., Vaughn, S., Tejero Hughes, M., \& Watson Moody, S. (2000). How effective are oneto-one tutoring programs in reading for elementary students at risk for reading failure? A metaanalysis of the intervention research. Journal of Educational Psychology, 92(4), 605.

Engzell, P., et al. (2020). Learning loss due to school closures during the COVID-19 pandemic. SocArXiv, 29 Oct. 2020. Web. https://osf.io/preprints/socarxiv/ve4z7/.

Escueta, M., Nickow, A. J., Oreopoulos, P., \& Quan, V. (2020). Upgrading education with technology: Insights from experimental research. Journal of Economic Literature, 58(4), 897-996.

Escueta, M., Quan, V., Nickow, A. J., \& Oreopoulos, P. (2017). Education technology: An evidencebased review.

Evidence for Learning. Small Group Tuition, viewed February 1, 2020, https://evidenceforlearning. org.au/the-toolkits/the-teaching-and-learning-toolkit/all-approaches/small-group-tuition/.

Faria, A. M., Sorensen, N., Heppen, J., Bowdon, J., \& Eisner, R. (2018). Getting students on track for graduation: Impact of the early warning intervention and monitoring system after one year. Society for Research on Educational Effectiveness.

Fernández Aráuz, A. (2020). Effects of COVID-19 on the Costa Rican educational system (Part I) (Efectos De La COVID-19 Sobre El Sistema Educativo Costarricense (I Parte). Retrieved December 4, 2020, from https://delfino.cr/2020/08/efectos-de-la-covid-19-sobre-el-sistema-edu cativo-costarricense-i-parte.

Garrote Sanchez, D., Gomez Parra, N., Ozden, C., Rijkers, B., Viollaz, M., \& Winkler, H. (2020). Who on earth can work from home?

Glewwe, P., Krutikova, S., \& Rolleston, C. (2017). Do schools reinforce or reduce learning gaps between advantaged and disadvantaged students? Evidence from Vietnam and Peru. Economic Development and Cultural Change, 65(4), 699-739. https://doi.org/10.1086/691993.

Global Education Advisory Panel. (2020). Cost-effective approaches to improve global learning. What does recent evidence tell us are "Smart Buys" for improving learning in low- and middleincome countries?

Griffith, A. K. (2020). Parental burnout and child maltreatment during the COVID-19 pandemic. Journal of Family Violence.

Heavey, L., Casey, G., Kelly, C., Kelly, D., \& McDarby, G. (2020). No evidence of secondary transmission of COVID-19 from children attending school in Ireland, 2020. Eurosurveillance, 25(21), 2000903. 
Hincapié, D. (2016). Do longer school days improve student achievement? Evidence from Colombia (No. IDB-WP-679). IDB Working paper series.

Ille, S. (2015). Private tutoring in Egypt: Quality education in a deadlock between low income, status and motivation. Egyptian Center for Economic Studies Working Paper No, 178.

Isaacs, D., Britton, P., Howard-Jones, A., Kesson, A., Khatami, A., Marais, B., Nayda, C., \& Outhred, A. (2020). To what extent do children transmit SARS-CoV-2 virus? Journal of Paediatrics and Child Health, 56(6), 978.

Jayachandran, S. (2014). Incentives to teach badly: After-school tutoring in developing countries. Journal of Development Economics, 108, 190-205.

Jensen, R. (2010). Impact of information on the returns to education on the demand for schooling in the dominican republic. Quarterly Journal of Economics, 125(2010), 515-548.

Jovanović, V., Marković-Čekić, J., Jokić, T., \& Ranković, T. (2017). Effectiveness of individualised support measures in the dropout prevention model (DPM) in Serbian schools. Psihološka Istraživanja, 20(1), 171-193.

Longden, K. (2013). Accelerated learning programmes: What can we learn from them about curriculum reform. Documento informativo para EFA Global Monitoring Report, 14.

Loureiro, A., \& Cruz, L. (2020). Achieving world-class education in adverse socioeconomic conditions: The case of Sobral in Brazil. World Bank.

Loureiro, A., Cruz, L., Lautharte, I., \& Evans, D. K. (2020). The State of Ceara in Brazil is a role model for reducing learning poverty. World Bank.

Ludvigsson, J. F. (2020). Children are unlikely to be the main drivers of the COVID-19 pandemic-A systematic review. Acta Paediatrica, 109(8), 1525-1530.

Maldonado, J., \& De Witte, K. (2020). The effect of school closures on standardised student test. FEB Research Report Department of Economics.

Mathematica. (2015). Do early warning systems and student engagement activities reduce dropout? Findings from the Four-Country SDPP Evaluation.

McLaughlin, B., \& Pitcock, S. (2009). Building quality in summer learning programs: Approaches and recommendations. Wallace Foundation.

Ministerio de Educación de Chile, Centro de Estudios. (2020). The COVID-19 impact on learning and schooling outcomes in Chile: Analysis based on a simulation tool provided by the World Bank (Impacto del COVID-19 en los Resultados de Aprendizaje y Escolaridad en Chile: Analisis con Base en Herramienta de Simulacion Proporcionada por el Banco Mundial). World Bank Group. http://documents.worldbank.org/curated/en/112721598898527225/Impacto-delCOVID-19-en-los-Resultados-de-Aprendizaje-y-Escolaridad-en-Chile-Analisis-con-Base-enHerramienta-de-Simulacion-Proporcionada-por-el-Banco-Mundial.

Mundy, K., \& Hares, S. (2020). Equity-focused approaches to learning loss during COVID-19. Center for Global Development Blog. Retrieved, 22.

Munro, A. P., \& Faust, S. N. (2020). Children are not COVID-19 super spreaders: Time to go back to school. Archives of Disease in Childhood, 105(7), 618-619.

Muralidharan, K., Singh, A., \& Ganimian, A. J. (2019). Disrupting education? Experimental evidence on technology-aided instruction in India. American Economic Review, 109(4), 14261460.

Murnane, R. J., \& Ganimian, A. (2014). Improving educational outcomes in developing countries: Lessons from rigorous impact evaluations. NBER Working Paper, (w20284); Agüero (2016).

Neilson, C., Gallego, F., \& Molina, O. (2016). Decidiendo para un futuro mejor: el efecto de la información sobre la deserción escolar y el uso del tiempo.

Nguyen, T. (2008). Information, role models and perceived returns to education: Experimental evidence from Madagascar. Unpublished Manuscript, 6.

Nickow, A., Oreopoulos, P., \& Quan, V. (2020). The impressive effects of tutoring on prek-12 learning: A systematic review and meta-analysis of the experimental evidence.

OECD, World Bank, Global Education Innovation Initative, \& hundrED. (2020). Lessons learned from Egypt during the pandemic: Implementing digital technologies to support remote learning 
and student assessment. Lessons for education- Joint Webinar series. http://pubdocs.worldbank. org/en/826771595269684475/Webinar-resources-Egypt-July-2020-finalv.pdf.

Onyango, M. A., Resnick, K., Davis, A., \& Shah, R. R. (2019). Gender-based violence among adolescent girls and young women: A neglected consequence of the West African Ebola outbreak. In Pregnant in the Time of Ebola (pp. 121-132). Springer.

Orkin, K. (2013). The effect of lengthening the school day on children's achievement in Ethiopia. Young Lives.

Patall, E. A., Cooper, H., \& Allen, A. B. (2010). Extending the school day or school year: A systematic review of research (1985-2009). Review of Educational Research, 80(3), 401-436.

Perera, M., \& Aboal, D. (2017). Evaluación del Impacto de la Plataforma Adaptativa de Matemática en los resultados de los aprendizajes1. Centro de Investigaciones Económicas, Montevideo.

Rajmil, L. (2020). Role of children in the transmission of the COVID-19 pandemic: a rapid scoping review. BMJ Paediatrics Open, 4(1).

Renaissance Learning, Education Policy Institute. (2021). Understanding progress in the 2020/21 academic year. Interim Findings.

Richardson, H. (2020). Coronavirus: £1bn catch-up tutoring fund for England's pupils. Viewed 20 January, 2020, https://www.bbc.com/news/education-53100881.

Robinson, C., Kraft, A., Loeb, S., \& Schueler, B. (2021). Accelerating student learning with highdosage tutoring. EdResearch for Recovery. Design Principles Series.

Shafiq, M. N. (2010). The effect of an economic crisis on educational outcomes: an economic framework and review of the evidence. Current Issues in Comparative Education, 12(2), 5-13.

Shores, K., \& Steinberg, M. (2017). The impact of the great recession on student achievement: evidence from population data. SSRN 3026151.

SIEF. (2020). Presenting the evaluations of the COVID-19 emergency window. http://pubdocs. wor ldbank.org/en/455991603752005286/COVID-winners92620.pdf.

Sierra Network. (2020). Dr. Moinina David Sengeh officially launched the zero schoolgirl pregnancy campaign. https://snradio.net/dr-moinina-david-sengeh-officially-launched-the-zero-schoolgirlpregnancy-campaign/.

Snipes, J., Huang, C. W., Jaquet, K., \& Finkelstein, N. (2016). The effects of the elevate math summer program on math achievement and algebra readiness. Society for Research on Educational Effectiveness.

Tomasik, M. J., Helbling, L. A., \& Moser, U. (2020). Educational gains of in-person vs. distance learning in primary and secondary schools: A natural experiment during the COVID-19 pandemic school closures in Switzerland. International Journal of Psychology.

UNESCO. (2020a). COVID-19 response-Re-enrolment: Identifying students at risk of dropout and encouraging a return to school, with a focus on equity and in particular, girls.

UNESCO. (2020b). COVID-19 response-Remediation: Helping students catch up on lost learning, with a focus on closing equity gaps.

UNESCO, UNICEF, \& The World Bank. (2020a). What have we learnt? Overview of findings from a survey of ministries of education on national responses to COVID-19. Paris, New York, Washington D.C.: UNESCO, UNICEF, World Bank.

UNESCO, UNICEF, \& The World Bank. (2020b). Survey on national education responses to COVID-19 school closures, round 2. Paris, New York, Washington D.C.: UNESCO, UNICEF, World Bank.

UNESCO, UNICEF, \& The World Bank. (2020c). UNESCO, UNICEF, World Bank survey of national education response to COVID-19 school closures. Consulted on: http://uis.unesco.org/ en/news/unesco-unicef-world-bank-survey-national-education-responses-covid-19-school-clo sures-key.

UNICEF, Early Warning Systems for Students at Risk of Dropping Out. (2018). Policy and practice pointers for enrolling all children and adolescents in school and preventing dropout. Viewed in: https://www.unicef.org/eca/sites/unicef.org.eca/files/2018-11/Early\%20w arning\%20systems \%20for\%20students\%20at\%20risk\%20of\%20dropping\%20out_0.pdf. 
Whitmire, R. (2020). New data: College enrollment for low-income high school grads plunged by $29 \%$ during the pandemic. The 74. Consulted 12 February 2021. https://www.the74million.org/ article/new-data-college-enrollment-for-low-income-high-school-grads-plunged-by-29-duringthe-pandemic/.

World Bank. (2019). Ending learning poverty: What will it take? World Bank, Washington, DC. World Bank. License: Creative Commons Attribution CC BY 3.0 IGO. http://hdl.handle.net/ $10986 / 32553$.

World Bank. (2020). World Bank education COVID-19 school closures map. Viewed in: https:// www.worldbank.org/en/data/interactive/2020/03/24/world-bank-education-and-covid-19.

World Bank. (2021). The costs of COVID-19 in education in Latin America and the Caribbean. Acting now to protect the human capital of our children.

Yarrow, N., Masood, E., \& Afkar, R. (2020). Estimates of COVID-19 impacts on learning and earning in Indonesia: How to turn the tide.

João Pedro Azevedo is a Lead Economist, EdTech Fellow and Education Statistics Coordinator from the World Bank Education Global Practice. He currently works on projects related to the measurement of learning poverty and human capital, the support to countries on how to accelerate learning, and the scale-up of population measures of educational outcomes. Before joining the World Bank, João Pedro served as the superintendent of Monitoring and Evaluation at the Secretary of Finance for the State of Rio de Janeiro, as well as a research fellow at the Institute of Applied Economic Research from the Brazilian Ministry of Planning (IPEA). While at IPEA, João Pedro led the design, implementation, and dissemination of the Monitoring and Evaluation systems for the Brazilian Adult Literacy program "Brazil Alfabetizado" from the Secretary of Adult Education at the Ministry of Education. Also, while in Brazil, João Pedro often worked with private sector foundations, such as Fundação Roberto Marinho and the Instituto Itaú-Unibanco on the design and evaluation of educational programs. He is a former chairman of the Latin American \& Caribbean Network on Inequality and Poverty and holds a Ph.D. in Economics.

Marcela Gutierrez has 10 years of experience designing, implementing, and evaluating human development programs and large-scale research projects in diverse country contexts. She is currently an Education Specialist at the Education Global Practice of the World Bank. Prior to this, she supported the implementation of the STEP Skills Measurement Survey and worked as an Advisor to the Ministry of Social Development and Inclusion in Peru and as a Consultant for the Interamerican Development Bank, UNRWA and Innovations for Poverty Action. She holds a master's degree in Public Administration and International Development from Harvard University and in Economics from Universidad de los Andes.

Rafael de Hoyos is a founding partner of Xaber, lecturer at the "Instituto Tecnológico Autónomo de México" (ITAM), and an economist in the education unit of the World Bank. He has published in peer-reviewed journals and advised governments on school-based management, evaluation policies, strategies to reduce dropout rates, and other topics. Previously, he was the chief of advisers to the under minister of education in Mexico (2008-11). Before joining the under ministry, he worked in the Development Economics Vice Presidency at the World Bank (2006-08), at the Judge Business School at the University of Cambridge (2005-06), and as a consultant for the United Nations Economic Commission for Latin America and the Caribbean in Mexico and at the United Nations World Institute for Development Economics Research in Finland. He holds an MA in development from the University of Sussex and a Ph.D. in economics from the University of Cambridge. 
Jaime Saavedra is the Global Director of Education at the World Bank. Between 2013 and 2016, he served as Minister of Education of Peru. During his tenure, comprehensive reform in basic education and in the university, system was implemented; Peru's performance improved substantially as measured by international learning assessments. He was Director for Poverty and Equity at the World Bank and co-led the work on the institution's twin goals of extreme poverty and shared prosperity. His research has focused on poverty and inequality, labor markets and economics of education. He was Executive Director of GRADE, a Peruvian think tank, has taught at Pontificia Universidad Catolina del Peru and has been Visiting Professor at the University of Toronto. He holds a Ph.D. in Economics from Columbia University and a BA in Economics from the Pontificia Universidad Católica del Perú.

Open Access This chapter is licensed under the terms of the Creative Commons Attribution 4.0 International License (http://creativecommons.org/licenses/by/4.0/), which permits use, sharing, adaptation, distribution and reproduction in any medium or format, as long as you give appropriate credit to the original author(s) and the source, provide a link to the Creative Commons license and indicate if changes were made.

The images or other third party material in this chapter are included in the chapter's Creative Commons license, unless indicated otherwise in a credit line to the material. If material is not included in the chapter's Creative Commons license and your intended use is not permitted by statutory regulation or exceeds the permitted use, you will need to obtain permission directly from the copyright holder.

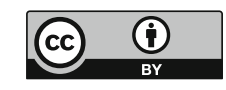

